\title{
Genetic Enhancement of Visual Learning by Activation of Protein Kinase C Pathways in Small Groups of Rat Cortical Neurons
}

\author{
Guo-rong Zhang, ${ }^{1}$ Xiaodan Wang, ${ }^{1}$ Lingxin Kong, ${ }^{1}$ Xiu-gui Lu, ${ }^{1}$ Brian Lee, ${ }^{1}$ Meng Liu, ${ }^{1}$ Mei Sun, ${ }^{1}$ Corinna Franklin, ${ }^{1}$ \\ Robert G. Cook, ${ }^{2}$ and Alfred I. Geller ${ }^{1}$ \\ ${ }^{1}$ Department of Neurology, West Roxbury Veterans Affairs Hospital/Harvard Medical School, West Roxbury, Massachusetts 02132, and ${ }^{2}$ Department of \\ Psychology, Tufts University, Medford, Massachusetts 02155
}

\begin{abstract}
Although learning and memory theories hypothesize that memories are encoded by specific circuits, it has proven difficult to localize learning within a cortical area. Neural network theories predict that activation of a small fraction of the neurons in a circuit can activate that circuit. Consequently, altering the physiology of a small group of neurons might potentiate a specific circuit and enhance learning, thereby localizing learning to that circuit. In this study, we activated protein kinase $\mathrm{C}$ (PKC) pathways in small groups of neurons in rat postrhinal (POR) cortex. We microinjected helper virus-free herpes simplex virus vectors that expressed a constitutively active PKC into POR cortex. This PKC was expressed predominantly in glutamatergic and GABAergic neurons in POR cortex. This intervention increased phosphorylation of five PKC substrates that play critical roles in neurotransmitter release (GAP-43 and dynamin) or glutamatergic neurotransmission (specific subunits of AMPA or NMDA receptors and myristoylated alanine-rich C kinase substrate). Additionally, activation of PKC pathways in cultured cortical neurons supported activation-dependent increases in release of glutamate and GABA. This intervention enhanced the learning rate and accuracy of visual object discriminations. In individual rats, the numbers of transfected neurons positively correlated with this learning. During learning, neuronal activity was increased in neurons proximal to the transfected neurons. These results demonstrate that potentiating small groups of glutamatergic and GABAergic neurons in POR cortex enhances visual object learning. More generally, these results suggest that learning can be mediated by specific cortical circuits.
\end{abstract}

Key words: visual learning; postrhinal cortex; protein kinase C; neurotransmitter release; glutamate receptor; herpes simplex virus vector

\section{Introduction}

Although learning theories hypothesize that memories are encoded by specific circuits (Dudai, 1989), it has proven difficult to localize learning to specific circuits within a forebrain area. The most precise localization established that spatial learning requires the dorsal quarter of hippocampus or NMDA receptors throughout CA1 (using ablation, Moser et al., 1995; using transgenic mice, Tsien et al., 1996). Neural network theories predict that activating a small fraction of the neurons in a circuit can activate that circuit (Rumelhart et al., 1986). Consequently, altering the physiology of small groups of neurons can potentiate a circuit and enhance learning, localizing learning to that circuit within a cortical area.

We hypothesized that activating protein kinase $\mathrm{C}(\mathrm{PKC})$ path-

Received April 11, 2005; revised July 10, 2005; accepted July 11, 2005.

This work was supported by National Institutes of Health Grants AG20177 (M.S.) and AG16777, AG021193, NS43107, and NS045855 (A.I.G.) and the National Science Foundation (R.G.C.). We thank Dr. J. Knopf for rat PKC $\beta$ | CDNA, Dr. A. Davison for HSV-1 cosmid set C, Dr. R. Sandri-Goldin for 2-2 cells, Dr. K. O'Malley for TH promoter, Dr. W. Schlaepfer for NF-H promoter, Dr. G. Felsenfeld for chicken $\beta$-globin insulator, Drs. I. Torgner and L. Hersh for antibodies, and Drs. K. Miczek and J. Haycock for critical reviews of the data.

Correspondence should be addressed to Dr. Alfred Geller, Research Building 3, West Roxbury Veterans Affairs Hospital/Harvard Medical School, 1400 VFW Parkway, West Roxbury, MA 02132. E-mail: alfred_geller@hms.harvard.edu.

DOI:10.1523/JNEUROSCI.2271-05.2005

Copyright $\odot 2005$ Society for Neuroscience $\quad$ 0270-6474/05/258468-14\$15.00/0 ways in small groups of rat postrhinal (POR) cortex neurons can potentiate the circuits containing these neurons, enhancing visual learning capability. Rat POR cortex and analogous areas in monkeys are required for visual object discrimination learning (Mishkin and Murray, 1994; Mumby and Pinel, 1994). Lesions including POR cortex impair acquisition of visual learning tasks (Mumby and Pinel, 1994; Bussey et al., 1999), POR cortex receives significant inputs from specific visual areas (Burwell and Amaral, 1998a), and POR cortex neurons are activated by visual stimuli (Wan et al., 1999) or stimulation of visual cortex (Naber et al., 2000).

PKC pathways are good candidates for causing changes in neuronal physiology that mediate learning. Specific PKC substrates play central roles in neurotransmitter release, glutamatergic neurotransmission, and signal transduction. PKC pathways regulate specific neurophysiological processes (Tanaka and Nishizuka, 1994). Pharmacological activation of PKC enhances release from neurons throughout the nervous system (Nichols et al., 1987; Waters and Smith, 2000). PKC inhibitors block longterm potentiation (LTP) (Malenka and Nicoll, 1999), and longterm depression (LTD) requires PKC-mediated phosphorylation of specific AMPA receptor subunits (Chung et al., 2003; Seidenman et al., 2003). Hippocampal PKC levels are altered during performance of hippocampal-dependent learning tasks, includ- 
ing visual discrimination in a water maze (Olds et al., 1990). PKC $\gamma$ knock-out mice display mild deficits in selected learning paradigms (Abeliovich et al., 1993), although impaired cerebellar development and motor coordination complicate interpretation (Chen et al., 1995; Kano et al., 1995). PKC $\beta$ knock-out mice display deficits in fear conditioning (Weeber et al., 2000).

Constitutively active PKCs have important roles in neuronal physiology. PKCs are activated by calpain cleavage (Kishimoto et al., 1989), and levels are increased during LTP (Powell et al., 1994). Constitutively active $\mathrm{PKC} \zeta$ is transcribed from an internal promoter (Hernandez et al., 2003) and is necessary for LTP (Ling et al., 2002). We reported a constitutively active catalytic domain of rat PKC $\beta$ II $(P k c \Delta)$ and a point mutation ( $\mathrm{Pkc} \Delta \mathrm{GG})$ lacking activity (Song et al., 1998). Pkc $\Delta$ increased neurotransmitter release from cultured sympathetic neurons (Song et al., 1998).

We report that genetic activation of PKC pathways in small groups of rat POR cortex neurons enhances visual object discrimination learning. $\mathrm{Pkc} \Delta$ was expressed in several hundred predominantly glutamatergic and GABAergic neurons in POR cortex (using a virus vector), increasing phosphorylation of five $\mathrm{PKC}$ substrates with critical roles in neurotransmitter release and glutamatergic neurotransmission. This intervention enhanced accuracy on visual discriminations, and, during learning, neuronal activity was increased in neurons near the transfected neurons.

\section{Materials and Methods}

Herpes simplex virus vectors and packaging. $\mathrm{pkc} \Delta$ contains the catalytic domain of rat PKC $\beta I I$ (nucleotide 994 to the $3^{\prime}$ end), and the flag tag was fused to the $5^{\prime}$ end of pkc $\Delta$ (Song et al., 1998, their Fig. 1). Pkc $\Delta$ GG contains a point mutation; a Gly replaced an absolutely conserved Lys residue, required for phosphoryl transfer (Hanks et al., 1988; Song et al., 1998). We expressed these constructs in the yeast Saccharomyces cerevisiae and used cell extracts to show that Pkc $\Delta$ exhibits a substrate specificity similar to rat brain PKC and that Pkc $\Delta$ GG lacks protein kinase activity (Song et al., 1998, their Tables 1, 2).

A modified neurofilament promoter supported recombinant gene expression (Zhang et al., 2000). An enhancer from the tyrosine hydroxylase promoter (TH) $(-0.5$ to $-6.8 \mathrm{~kb})$ was fused to the $5^{\prime}$ end of the neurofilament heavy gene promoter (NFH) $(0.6 \mathrm{~kb})$; and the chicken $\beta$-globin insulator (INS) $(1.2 \mathrm{~kb})$ was fused to the $5^{\prime}$ end of the TH enhancer (Zhang et al., 2000). This promoter (INS-TH-NFH promoter) supported expression in forebrain neurons for 6 or 14 months, the longest times examined, and time courses in the striatum and the hippocampus documented expression in similar numbers of cells at times approximating the beginning and end of the testing of new object sets (Zhang et al., 2000; Sun et al., 2004) (supplemental Table S1, available at www.jneurosci.org as supplemental material).

pINS-TH-NFHpkc $\Delta \backslash$ INS-TH-NFHlac (Wang et al., 2001) contains two transcription units; one transcription unit contains pkc $\Delta$ and the other contains $\operatorname{Lac} Z$, to facilitate detection of cells that contain the vector. This vector coexpresses $\beta$-galactosidase ( $\beta$-gal) and $\mathrm{Pkc} \Delta$ in POR cortex cells (Wang et al., 2001); $96 \%$ of the positive cells costained for $\beta$-gal-immunoreactivity (IR) and flag-IR. pINS-TH-NFHpkc $\Delta$ GGIINSTH-NFHlac was constructed using the same strategy as for pINS-THNFHpkc $\Delta \backslash$ INS-TH-NFHlac (Wang et al., 2001), except pHSVpkc $\Delta$ GG (Song et al., 1998) replaced pHSVpkc $\Delta$. pINS-TH-NFHlac (Zhang et al., $2000)$ is a control vector that expresses $\beta$-gal.

Helper virus-free herpes simplex virus (HSV-1) vector packaging was performed as described previously (Fraefel et al., 1996), and the vector stocks were purified and titered (Zhang et al., 2000; Wang et al., 2001). The titers were $1.2 \pm 0.1 \times 10^{7}$ (mean \pm SEM) infectious vector particles per milliliter. In each experiment, the titers of the different vector stocks were matched by dilution. No HSV $-1(<10 \mathrm{pfu} / \mathrm{ml})$ was detected in any of these vector stocks.

$\mathrm{Pkc} \Delta$ is derived from the rat PKC $\beta \mathrm{II}$ isoform (Song et al., 1998), and $\mathrm{PKC} \beta$ knock-out mice display deficits in fear conditioning (Weeber et al., 2000). Pkc $\Delta$ lacks the regulatory domain that controls the activity of the PKC $\beta$ isoforms and targets them to specific subcellular locations (Tanaka and Nishizuka, 1994). Also, Pkc $\Delta$ is expressed from a heterologous promoter, a modified neurofilament promoter (Zhang et al., 2000). Because of these differences in cellular localization, subcellular localization, and regulation of activity, it is not surprising that the Pkc $\Delta$ in POR cortex condition reported below and PKC $\beta$ knock-out mice display different changes in neuronal physiology and learning. The catalytic domains of all of the PKC isoforms are highly homologous (Tanaka and Nishizuka, 1994), and Pkc $\Delta$ has activity for each of the eight PKC substrates that have been examined (Song et al., 1998; this study). Thus, use of a catalytic domain from a different PKC isoform in the paradigm reported here might yield similar results.

Neurotransmitter release. Cultures of dissociated temporal cortex cells were prepared from embryonic day 17 Sprague Dawley rats (Dichter, 1978; Wang et al., 2002) and maintained in Neurobasal medium with B-27 supplement (NB medium) (lacks Glu, Gln, and GABA; Invitrogen, Carlsbad, CA) and $0.5 \mathrm{~mm}$ Gln (omitted during the release procedure). Cultures were treated with $10 \mu \mathrm{M}$ cytosine arabinoside (days 3-4) and infected (multiplicity of infection, 0.2 ) on day 8 or 9 , and release of Glu (Feasey et al., 1986; Di Iorio et al., 1996) and GABA (Snodgrass et al., 1980) was measured $24 \mathrm{~h}$ later. Cultures were incubated $\left(15 \mathrm{~min}, 37^{\circ} \mathrm{C}\right)$ in $\mathrm{NB}$ medium containing $\left[{ }^{14} \mathrm{C}(\mathrm{U})\right]-\mathrm{L}-\mathrm{Glu}(0.73 \mu \mathrm{M}, 273 \mathrm{mCi} / \mathrm{mmol}$; PerkinElmer, Shelton, CT) and $\left[2,3-{ }^{3} \mathrm{H}(\mathrm{N})\right]$-GABA $(0.03 \mu \mathrm{M}, 27.6 \mathrm{Ci} /$ mmol; PerkinElmer). Cultures were washed twice (all subsequent incubations at room temperature), incubated in NB medium (15 min, two times; then $3 \mathrm{~min}$, five times; fractional efflux was stable during the last four incubations), incubated in NB medium containing $600 \mu \mathrm{M}$ 4-aminopyridine (4-AP) [3 min, three times (Mitterdorfer and Bean, 2002); Sigma, St. Louis, MO], incubated in NB medium (3 min, three times), and lysed (10 mm EDTA, $1 \%$ SDS, and $10 \mathrm{~mm}$ Tris $\mathrm{HCl}, \mathrm{pH} 8.0$ ). The no-calcium condition was NB medium containing 5.5 mm EGTA. Radioactivity was quantified by liquid scintillation spectroscopy $(<10 \%$ overlap between ${ }^{14} \mathrm{C}$ and ${ }^{3} \mathrm{H}$ channels), and fractional efflux was calculated as the percentage of total radioactivity per well. Basal efflux was calculated as the average fractional efflux for the two incubations before 4-AP treatment. 4-AP-dependent release was calculated as the ratio of 4-AP treatment/basal efflux. With mock infection, the basal efflux for Glu and GABA was 2.4 and 2.5\%, respectively (similar before and after 4-AP treatment), and 4-AP-dependent release was 168 and 170\%, respectively (relative to basal efflux). Each condition was in triplicate and the experiment was repeated twice (six wells per condition total). As used within the context of 4-AP-stimulated efflux over a period of $3 \mathrm{~min}$, "release" is not intended to represent either the initial rates of secretion or those processes underlying the rapid kinetics of synaptic transmission.

Gene transfer. Vector stocks were delivered into male Long-Evans rats (initially 100-125 gm; Charles River Laboratories, Wilmington MA) by stereotactic injection (two sites, one per hemisphere, $3 \mu \mathrm{l} /$ site) into either POR cortex [anteroposterior (AP), -8.0 ; mediolateral (ML), \pm 6.0 ; dorsoventral (DV), -5.2] or primary somatosensory (SSp) cortex (AP, -2.3 ; $\mathrm{ML}, \pm 1.5 ; \mathrm{DV},-2.0)$. AP is relative to bregma, $\mathrm{ML}$ is relative to the sagittal suture, and DV is relative to the bregma-lambda plane (Paxinos and Watson, 1986). These studies were approved by the West Roxbury Veterans Affairs Hospital and Children's Hospital Institutional Animal Care and Use Committees.

Visual testing apparatus. Each of 12 operant chambers was enclosed within a $76 \mathrm{~cm}$ box (FIS units; Plas Labs, Lansing, MI) that contained an overhead fluorescent light and speaker located on the rear panel. A ventilation fan provided masking white noise. A computer located outside of each test box controlled and recorded experimental events. A touchscreen (IRFP-10.4; Elotouch Systems, Menlo Park, CA) was centered on one of the long sides of a clear plastic rat cage $(46 \mathrm{~cm}$ length $\times 20 \mathrm{~cm}$ height $\times 24 \mathrm{~cm}$ depth) and placed directly in front of a computer monitor. A liquid feeder (ENV-110 and ENV-201A; Med Associates, Lafayette, IN) was mounted in the center of the wall opposite the computer monitor. A lever (ENV-110; Med Associates) was mounted underneath the feeder. For additional details, see Cook et al. (2004, their Methods).

Visual testing. For additional details, see Cook et al. (2004, their Methods). The rats were encoded at the beginning of each experiment, before 
the first training session. This blind code was used to identify the rats to both the computer and the computer operator throughout the experiment. The rats were maintained on moderate food deprivation $(8 \mathrm{gm} / \mathrm{d}$ per rat), and water was available ad libitum (Cook et al., 2004).

As an overview, initial training was performed to familiarize the rats with the apparatus (Cook et al., 2004); the rats were then trained to discriminate between horizontal versus vertical bars (三vs $\| \mid$ ). Gene transfer was performed, the rats were retested on this orientation discrimination, and then the rats were tested on a new object set(s). For each visual discrimination trial, the rats pressed a lever to obtain an object set and pressed a touchscreen to choose an object, and correct responses were reinforced with both sound and food (Cook et al., 2004). Each experiment required $\sim 2$ months: $\sim 1$ month for the training before gene transfer, and $\sim 1$ month for the gene transfer, recovery, and the visual testing after gene transfer.

For simultaneous two-object visual discrimination training, each trial was started by the rat depressing the lever, causing the stimuli to appear on the screen. The location of a specific image in an object set was pseudorandomly varied between the left or right side of the display, with no more than three consecutive presentations on one side and counterbalanced over blocks of 20 presentations. Making contact with the correct stimulus in the touchscreen resulted in the speaker emitting a sound (1s) and a milk reward $(0.1 \mathrm{~s}$; four consecutive correct responses caused the reward amount to double until the next error). An incorrect response caused the overhead house light to be turned off for $15 \mathrm{~s}$, and a large $(23.5 \times 10.1 \mathrm{~cm})$ solid rectangle flashed on the monitor three times (for only the initial acquisition of $\equiv$ vs \|\| , a timeout of $3 \mathrm{~s}$ was used for the first two sessions only). A correction procedure was also used, with every fourth incorrect response causing a re-presentation of a trial. Each daily session consisted of 120 discrimination trials, and the rats were trained 7 $\mathrm{d} /$ week. For each object set, a specific object was always correct; because performance with either object as correct is similar (Markham et al., 1996), counterbalancing was not used. Objects were as follows: $\equiv$ and || , described previously (Cook et al., 2004); $\square, 6.7 \mathrm{~cm}$ external side $\times 0.6$ $\mathrm{cm}$ wide;,$+ 6.4 \times 1.3 \mathrm{~cm}$ for each bar; / and $\backslash, 8.3 \times 1.0 \mathrm{~cm}\left(45^{\circ}\right.$ or $135^{\circ}$ for long side); $\lrcorner, \top$, and $\perp, 6.4 \mathrm{~cm}$ horizontal bar, $1.3 \mathrm{~cm}$ vertical bar, and $0.8 \mathrm{~cm}$ wide for both bars.

The experiments were designed to control for any differences in learning ability among the rats. The rats were assigned to sets of three based on how quickly they acquired $\equiv$ versus $\|$, and, within each set, they were randomly assigned to one of three groups $[\mathrm{Pkc} \Delta$, vector system control (Pkc $\Delta \mathrm{GG}$ or $\beta$-gal only), or no gene transfer (PBS or no surgery)]. Rats received $4 \mathrm{~d}$ of food ad libitum, gene transfer, $4 \mathrm{~d}$ of food ad libitum, $2 \mathrm{~d}$ of moderate food deprivation, and then visual testing (Cook et al., 2004). Approximately three-quarters of the rats completed the protocol, and almost all subject attrition occurred either during training before gene transfer or immediately after the surgery. Twenty minutes before the start of selected sessions, specific rats received dizocilpine (MK-801; 0.2 $\mathrm{mg} / \mathrm{kg}$, i.p.; Sigma).

Data analysis. The data collection and analysis was performed entirely by computer. Data analysis used macros in Excel (Microsoft, Seattle, WA). The data were exported from Excel into Sigma Stat (SPSS, Chicago, IL) for statistical analysis. Statistical analyses were performed using between groups or repeated measures ANOVAs. Planned comparisons between the numbers of 5-bromo-4-chloro-3-indoyl- $\beta$-D-galactopyranoside (X-gal)positive cells and the learning were evaluated using Pearson's product moment correlations. Each data set was analyzed at least two times to ensure correctness.

In the Pkc $\Delta$ in POR cortex/ $\square$ versus + group ( $n=33$ rats), data from five rats were excluded from the behavioral analyses because these rats had no needle tracks or X-gal-positive cells (one rat), injection sites outside of POR cortex (three rats), or substantial necrosis around the needle tracks (one rat). Including these rats in the Pkc $\Delta$ in POR cortex group still results in a statistically significant enhancement in learning (sessions $6-10, \mathrm{Pkc} \Delta$ in POR cortex vs combined control group, $p<0.01$ ).

Immunohistochemistry. The rats were perfused with $50 \mathrm{ml}$ of PBS and then $200 \mathrm{ml}$ of $4 \%$ paraformaldehyde in PBS. The brains were postfixed in $4 \%$ paraformaldehyde in PBS $\left(4 \mathrm{~h}, 4^{\circ} \mathrm{C}\right)$ and cryoprotected in $25 \%$ sucrose in PBS $\left(2 \mathrm{~d}, 4^{\circ} \mathrm{C}\right)$, and $25 \mu \mathrm{m}$ coronal sections were cut using a freezing microtome. Enzymatic staining and immunohistochemistry were performed on free-floating sections. X-gal (Sigma) staining was performed as described previously (Zhang et al., 2000).

For immunohistochemistry, sections were incubated in PBS and $0.3 \%$ $\mathrm{H}_{2} \mathrm{O}_{2}$ (10 min, room temperature) and then rinsed in PBS (three times, 5 min each). Sections were permeabilized by incubation in PBS, $2 \%$ normal goat serum, and $0.2 \%$ Triton $\mathrm{X}-100$ (buffer $\mathrm{A} ; 30 \mathrm{~min}, 37^{\circ} \mathrm{C}$ ) and then incubated overnight $\left(4^{\circ} \mathrm{C}\right)$ in buffer A with a primary antibody (listed below). The sections were rinsed in PBS and $0.2 \%$ Triton X-100 (buffer B; three times, 10 min each, room temperature) and then incubated in buffer B with biotinylated goat anti-mouse IgG or goat antirabbit IgG (1:200 dilution; $2 \mathrm{~h}$, room temperature; Vector Laboratories, Burlingame, CA). The sections were rinsed with buffer B (three times, 10 min each, room temperature), incubated with the $A B C$ reagent $(1 \mathrm{~h}$, room temperature; Vector Laboratories), and rinsed with PBS. Immunoreactivity was visualized with diaminobenzidene according to the instructions of the manufacturer (Vector Laboratories).

For immunofluorescent visualization, sections were permeabilized as just described and then incubated with primary antibodies (listed below) in buffer A (overnight, $4^{\circ} \mathrm{C}$; then $1 \mathrm{~h}, 37^{\circ} \mathrm{C}$ ). Sections were washed with PBS (three times, $5 \mathrm{~min}$ each) and then incubated with the appropriate combination of fluorescein isothiocyanate- or rhodamine isothiocyanate-conjugated goat anti-rabbit IgG, or goat anti-mouse IgG, or rabbit anti-goat IgG (1:150 dilutions; Jackson ImmunoResearch, West Grove, PA) in buffer A ( $3 \mathrm{~h}$, room temperature). Sections were washed with PBS (three times, 5 min each), mounted in PBS, and immediately examined under the microscope.

The primary antibodies were as follows: rabbit anti- $\beta$-gal (1:1000 dilution; ICN, Aurora, $\mathrm{OH})$; mouse monoclonal anti- $\beta$-gal (1:500 dilution; Sigma); mouse monoclonal anti-flag (1:500 dilution; Sigma); mouse monoclonal anti-neuronal-specific nuclear protein $(\mathrm{NeuN})(1$ : 200 dilution; Chemicon, Pittsburg, PA); rabbit anti-phosphate-activated glutaminase (1:200 dilution; gift from Dr. I. A. Torgner, University of Oslo, Oslo, Norway); rabbit anti-glutamic acid decarboxylase (GAD) (1:500 dilution; Chemicon); rabbit anti-choline acetyltransferase (ChAT) (1:300 dilution; gift from Dr. L. B. Hersh, University of Kentucky, Lexington, KY); mouse monoclonal anti-TH (1:500 dilution; Roche, Indianapolis, IN); goat anti-GAP-43-Ser41-P, goat anti-GAP-43, rabbit anti-dynamin-Ser795-P, rabbit anti-dynamin, rabbit anti-NMDA receptor NR $\zeta 1$, rabbit anti-myristoylated alanine-rich $C$ kinase substrate (MARCKS)-Ser159/163-P, goat anti-MARCKS, and goat anti-calcium/ calmodulin-dependent kinase II (CaMKII)-Thr286-P (1:200 dilutions; Santa Cruz Biotechnology, Santa Cruz, CA); rabbit anti-glutamate receptor subtype 2 (GluR2)-Ser880-P, rabbit anti-GluR2/3, and rabbit antiNR1-Ser896-P (1:200 dilutions; Upstate Biotechnology, Lake Placid, NY); rabbit anti-c-fos (1:300 dilution; Calbiochem, San Diego, CA); mouse monoclonal anti-c-fos (1:500 dilution; Oncogene, Cambridge, MA); goat anti-Arc (1:300 dilution; Santa Cruz Biotechnology); and rabbit anti-Zif268 (1:400 dilution; Santa Cruz Biotechnology).

Western blots. Western blots were performed as described previously (Oh et al., 2003). Protein extracts were prepared from the areas around injection sites using CelLyticMT and protease inhibitor cocktail (Sigma), following the instructions of the manufacturer. Each sample was mixed with Laemmli's sample buffer $(1: 1)$ and treated at $95^{\circ} \mathrm{C}$ for $5 \mathrm{~min}$, and 10 $\mu \mathrm{g}$ was loaded onto each lane of a gel. SDS-PAGE was performed using a $10 \%$ gel under reducing conditions, and proteins were transferred to an Immuno-Blot polyvinylidene difluoride membrane (Bio-Rad, Hercules, CA). The membrane was incubated with either rabbit anti-dynaminSer795-P (1:500 dilution) or rabbit anti-dynamin (1:1000 dilution), followed by an HRP-conjugated goat anti-rabbit IgG (1:5000 dilution), and visualized using ECL Western Blotting Detection Reagents (Amersham Biosciences, Piscataway, NJ). The bands were subjected to densitometry scanning, and the density of the band from each Pkc $\Delta$ or Pkc $\Delta$ GG rat was divided by the density of the band from a no-surgery rat.

Vector DNA and recombinant RNA analyses. For PCR analysis of vector DNAs, DNA was extracted (Song et al., 1998) from coronal sections that contained POR cortex and adjacent cortical areas. The PCR conditions and primers were as described previously (Song et al., 1998), except a primer from the mouse neurofilament heavy gene promoter (nucleotides 

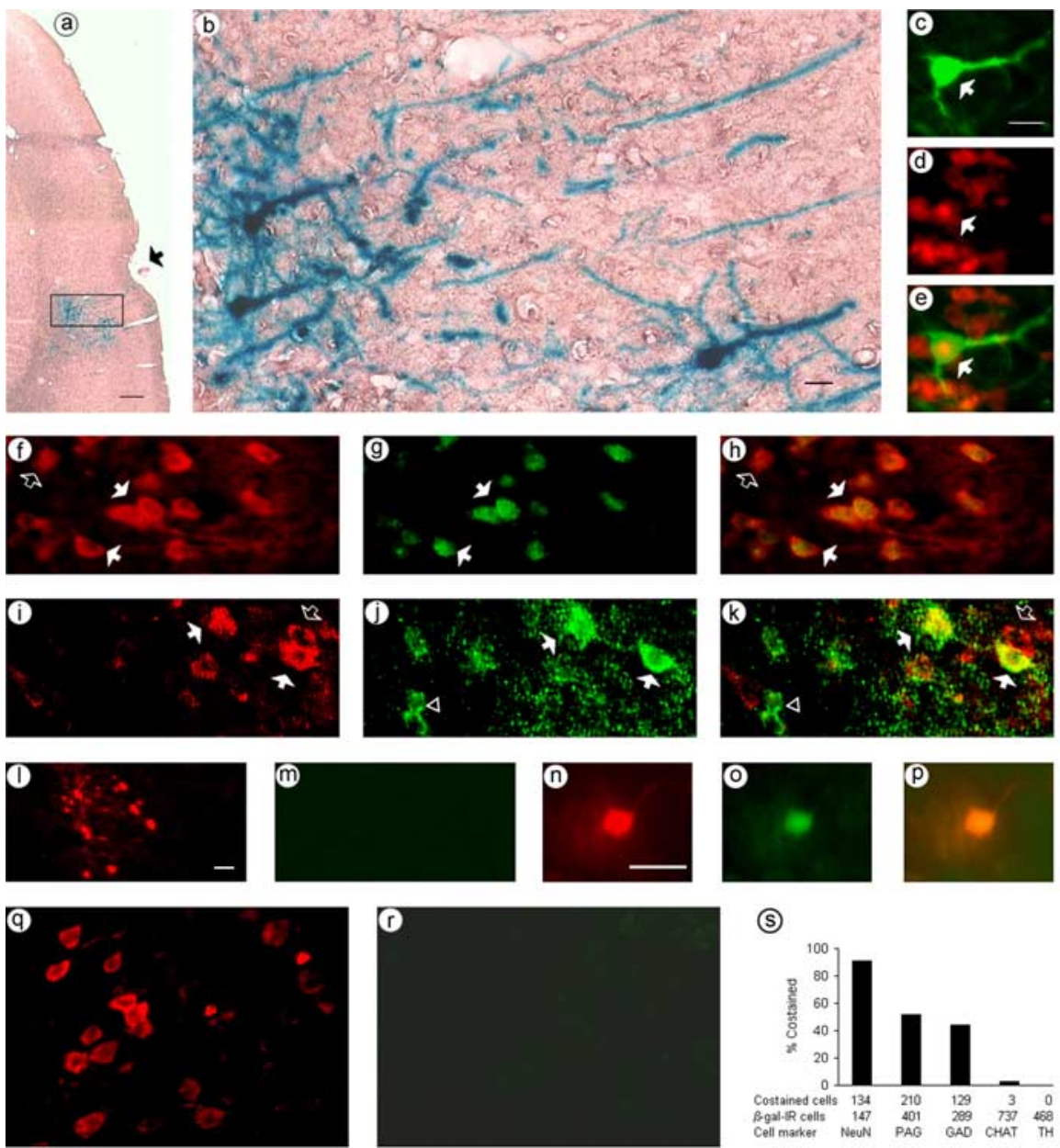

Figure 1. Recombinant gene expression was targeted to glutamatergic and GABAergic neurons in POR cortex. The rats were killed at $4 \mathrm{~d}$ after gene transfer. $\boldsymbol{a}$, A low-power view shows X-gal-positive cells in POR cortex. The arrow indicates the rhinal sulcus. $\boldsymbol{b}$, A high-power view shows X-gal-positive cells with neuronal morphology, including pyramidal cell bodies and apical dendrites (the boxed area from $\boldsymbol{a}$ is shown). $\boldsymbol{c}-\boldsymbol{e}$, Neuronal-specific expression: $\beta$-gal-IR $(\boldsymbol{c})$, NeuN-IR (d), merged (e). Filled arrows, Costained cells; open arrows, $\beta$-gal-IR only; open arrowheads, cell marker-IR only. $\boldsymbol{f}$ - $\boldsymbol{h}$, Glutamatergic neuron-specific expression: $\beta$-gal-IR $(\boldsymbol{f})$, phosphate-activated glutaminase-IR $(\boldsymbol{g})$, merged $(\boldsymbol{h})$. $\boldsymbol{i}$ - $\boldsymbol{k}$, GABAergic neuron-specific expression: $\beta$-gal-IR $(\boldsymbol{i})$, GAD-IR $(\boldsymbol{j})$, merged $(\boldsymbol{k})$. $\boldsymbol{I}-\boldsymbol{p}$, Cholinergic neuron-specific expression: $\beta$-gal-IR $(\boldsymbol{I})$, this field lacks ChAT-IR $(\boldsymbol{m})$, and one $\beta$-gal-IR cell $(\boldsymbol{n})$, ChAT-IR (o), merged $(\boldsymbol{p}) . \boldsymbol{q}, \boldsymbol{r}$, Catecholaminergic neuron-specific expression: $\beta$-gal-IR $(\boldsymbol{q})$, TH-IR (r). $\mathbf{s}$, Cell counts of the distribution of $\beta$-gal-IR in different cell types. PAG, Phosphate-activated glutaminase. Scale bars: $\boldsymbol{a}, 200 \mu \mathrm{m} ; \boldsymbol{b}, 25$ $\mu \mathrm{m}$; (in c) $\boldsymbol{c}-\boldsymbol{k}, \boldsymbol{q}, \boldsymbol{r}, 25 \mu \mathrm{m}$; (in I) $\boldsymbol{I}, \boldsymbol{m}, 50 \mu \mathrm{m}$; (in $\boldsymbol{n}) \boldsymbol{n}-\boldsymbol{p}, 25 \mu \mathrm{m}$.

-297 to -271 ) replaced the primer from the HSV-1 immediate early (IE) 4/5 intron; each set of primers is specific for pkc $\Delta$-containing vector sequences and does not support amplification of the endogenous rat PKC $\beta$ gene. PCR products were visualized by Southern analysis.

For reverse transcriptase (RT)-PCR analysis of pkc $\Delta$ RNA, RNA was extracted from brain fragments that contained POR cortex and adjacent cortical areas (no hippocampus or subcortical areas) using the RNeasy Mini kit (Qiagen, Valencia, CA). RT-PCR was performed using the One Step RT-PCR kit (Qiagen) and the second set of primers for PCR (Song et al., 1998). RT-PCR products were visualized by Southern blot analysis. In situ hybridization was performed as described previously (Song et al., 1998).

\section{Results}

\section{Gene transfer into neurons in POR cortex}

Gene transfer was effected by using a helper virus-free HSV-1 vector system (Fraefel et al., 1996) and a previously described vector that coexpresses Pkc $\Delta$ and $\beta$-gal (Wang et al., 2001). This vector uses a modified neurofilament heavy gene promoter that supports long-term expression in forebrain neurons (Zhang et al., 2000). This vector coexpresses $\beta$-gal and Pkc $\Delta$ in POR cortex cells (Wang et al., 2001).

We determined the locations and types of transfected cells after microinjection of this vector into POR cortex. Rats were killed at $4 \mathrm{~d}$ after gene transfer (one injection site per hemisphere), and positive cells were visualized using sensitive assays for $\beta$-gal. We observed groups of X-galpositive cells proximal to the injection sites in POR cortex (Fig. 1a). Many of these cells displayed neuronal morphology, including pyramidal cell bodies and apical dendrites (Fig. 1b). We identified the types of cells that were transfected by costaining sections for $\beta$-gal-IR and markers for specific types of cells. Recombinant gene expression in neurons was assayed by costaining for $\beta$-gal and NeuN (Fig. $1 c-e$ ). Expression in glutamatergic neurons was assayed by costaining for $\beta$-gal and phosphate-activated glutaminase (Kaneko et al., 1995) (Fig. 1f-h), and expression in GABAergic neurons was assayed by costaining for $\beta$-gal and GAD (Fig. 1 $i-k$ ). Expression in cholinergic neurons was assayed by costaining for $\beta$-gal and ChAT (Fig. $1 l-p$ ), and expression in catecholaminergic neurons was assayed by costaining for $\beta$-gal and TH (Fig. 1q,r). Cell counts (Fig. 1s) established that $\sim 91 \%$ of the transfected cells were neurons, $\sim 52 \%$ were glutamatergic and $\sim 45 \%$ were GABAergic, $<1 \%$ were cholinergic, and no TH-immunoreactive cells were detected in POR cortex, consistent with previous reports (Hokfelt et al., 1984).

We were concerned that recombinant gene expression in other brain areas could potentially affect learning. Most previous studies with HSV-1 vectors reported that the preponderance of recombinant gene expression was proximal to the injection site, with only low levels of expression at distant sites, attributable to retrograde transport of HSV-1 vectors through axons. Nonetheless, we directly addressed this concern by assaying for recombinant gene expression in specific cortical areas that project to POR cortex and in specific subcortical areas. Rats were killed at $4 \mathrm{~d}$ after microinjection of vector into POR cortex, and $\sim 300 \beta$-gal-immunoreactive cells were observed in each POR cortex (data not shown). Small numbers (one to four) of $\beta$-gal-immunoreactive cells were observed in specific cortical areas with large projections to POR cortex (Fig. $2 a-c)$. In particular, perirhinal cortex, which has a major projection to POR cortex (Burwell and Amaral, 1998b), contained only $\sim 1 \%$ of the number of $\beta$-gal-immunoreactive cells as POR cortex. No $\beta$-gal-immunoreactive cells were observed in any of the subcortical areas examined, including the hippocampus, amygdala, specific cholinergic basal forebrain areas, and specific catecholaminergic midbrain areas (Fig. $2 d-j$ ).

Together, these results demonstrate that, after microinjection of this vector into POR cortex, the vast majority of recombinant 

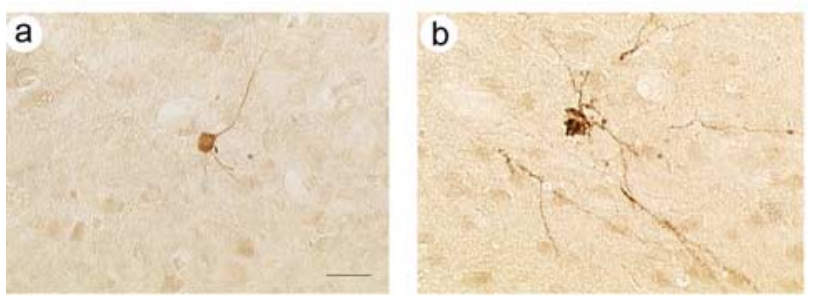

C Specific cortical areas with large projections to POR cortex contain $\sim 1 \%$ of the number of B-gal-IR cells as POR cortex

\begin{tabular}{lcc}
\hline Cortical Area & Density of projection to POR cortex (cells $\left./ \mathrm{mm}^{3}\right)$ & B-gal-IR cells \\
\hline Perirhinal cortex & $>2,000$ & + \\
Posterior parietal cortex & $>2,000$ & + \\
Lateral visual association cortex & $>2,000$ & + \\
Medial visual association cortex & $>2,000$ & + \\
Ventral temporal cortex & $1,500-1,999$ & + \\
Dorsal retrosplenial cortex & $1,000-1,499$ & + \\
Lateral entorhinal area & $500-999$ & + \\
Medial entorhinal area & $500-999$ & - \\
Primary visual cortex & $500-999$ & - \\
Auditory association cortex & $500-999$ & \\
\hline
\end{tabular}

+, 1-4 B-gal-IR cells; -, no ß-gal-IR cells.
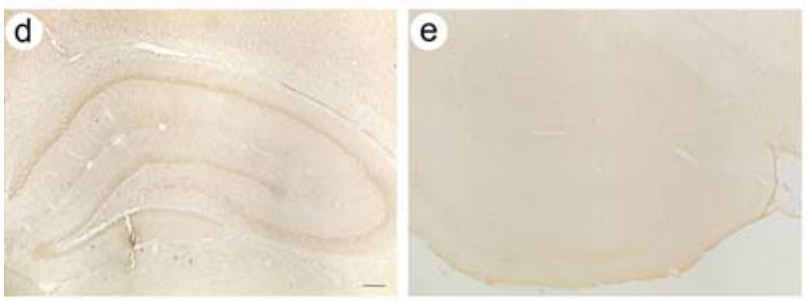

(j) Specific subcortical areas that lack B-gal-IR cells in rats sacrificed 4 days after microinjection of vector into POR cortex
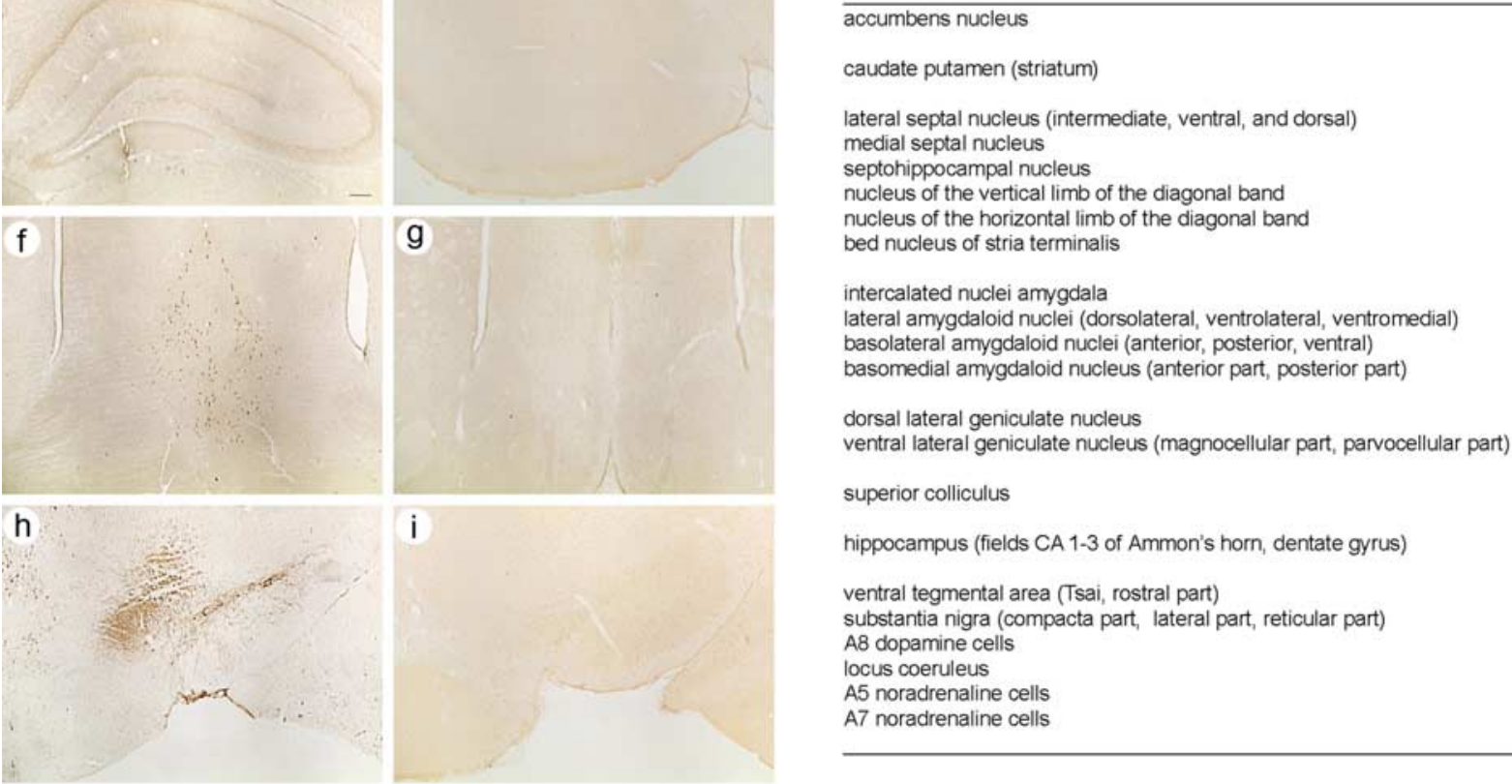

Figure 2. Minimal recombinant gene expression was detected in specific cortical areas that project to POR cortex, and no recombinant gene expression was observed in specific subcortical areas. The rats were killed at $4 \mathrm{~d}$ after microinjection of vector into POR cortex. $\boldsymbol{a}, \boldsymbol{b}$, High-power views show two $\beta$-gal-immunoreactive cells, one each in perirhinal cortex (a) and lateral visual association cortex $(\boldsymbol{b})$. c, Summary of the cortical areas that contain or lack $\beta$-gal-immunoreactive cells. The nomenclature for cortical areas, and the densities of the projections to POR cortex, are according to Burwell and Amaral (1998a). $\boldsymbol{d}, \boldsymbol{e}$, Low-power views show no $\beta$-gal-immunoreactive cells in either hippocampus (d) or amygdala (e).f, $\boldsymbol{g}$, Basal forebrain: ChAT-IR identifies the medial and lateral septum $(\boldsymbol{f})$, and no $\beta$-gal-immunoreactive cells were detected in an adjacent section $(\boldsymbol{g}) . \boldsymbol{h}, \boldsymbol{i}$, Midbrain: TH-IR identifies the substantia nigra pars compacta and ventral tegmental area $(\boldsymbol{h})$, and no $\beta$-gal-immunoreactive cells were detected in an adjacent section $(\boldsymbol{i})$.j, Summary of the subcortical areas that lack $\beta$-gal-immunoreactive cells. The nomenclature is according to Paxinos and Watson (1986). Scale bars: $\boldsymbol{a}, \boldsymbol{b}, 25 \mu \mathrm{m} ; \boldsymbol{d}-\boldsymbol{i}, 200 \mu \mathrm{m}$.

gene expression is in glutamatergic and GABAergic neurons in POR cortex. Thus, any changes in learning that may occur after gene transfer are most likely attributable to the effects of $\mathrm{Pkc} \Delta$ on the physiology of glutamatergic and/or GABAergic neurons in POR cortex.

\section{Recombinant gene expression was maintained for the time required for visual testing}

In most experiments, new object sets were learned between 2 and 4 weeks after gene transfer (detailed below). Using PCR, we showed that vector DNA is present in the POR cortex of rats killed after visual testing (Fig. $3 a$ ). Furthermore, we documented long-term recombinant gene expression using five different assays, RT-PCR, in situ hybridization, X-gal staining, $\beta$-gal-IR, and flag-IR. Using RT-PCR, pkc $\Delta$ RNA was detected in the POR cortex of rats killed at 3 weeks after gene transfer (Fig. $3 A$ ). The bands produced from samples isolated from three rats (Rats 1-3 lanes) comigrated with the band produced using plasmid DNA as template (plasmid DNA lane). The signal was from RNA, and not from DNA, because a reaction that omitted the RT lacked the band (Rat 3 no RT lane). No band was observed in the absence of any RNA sample or plasmid DNA (no template lane). Using in situ hybridization, recombinant RNAs were localized to POR cortex cells in rats killed after visual testing (Fig. $3 b$ ); the hybridization probe recognizes the $3^{\prime}$ untranslated region in both pkc $\Delta$ and Lac Z RNAs. No signal was observed if the hybridization probe was omitted (Fig. 3c). Also, no signal was observed in the entorhinal cortex of rats that received $\operatorname{Pkc} \Delta$ (Fig. $3 d$ ) or in the POR cortex of no-surgery rats (Fig. $3 e$ ). Additionally, both $\beta$-gal and $\mathrm{Pkc} \Delta$ proteins were detected in rats killed after visual testing; $\mathrm{X}$-gal-positive cells were observed (Fig. $3 f$ ), cells that coexpress $\beta$-gal-IR and flag-IR [ $\operatorname{Pkc} \Delta$ contains the flag tag (Song et al., 1998)] were observed (Fig. $3 g-i$ ), and $\beta$-gal-IR was localized to neurons (Fig. 3j-l). Furthermore, in rats killed at 3 weeks after 
(a)
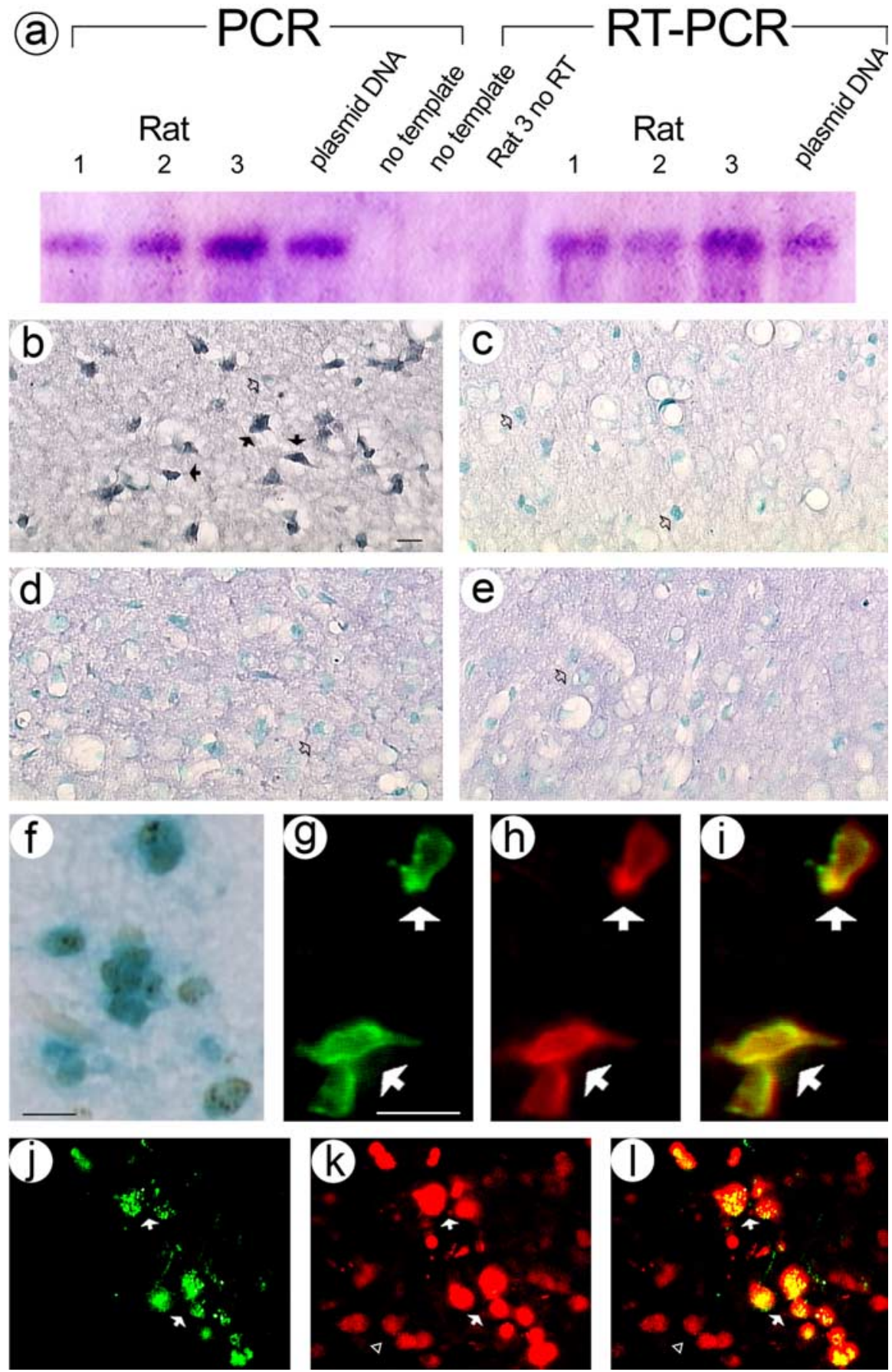

Figure 3. Long-term recombinant gene expression in POR cortex neurons. $\boldsymbol{a}, \mathrm{PCR}$ analysis of pkc $\Delta$ vector DNA and RT-PCR analysis of pkc $\triangle$ RNA. The rats were killed at 3 weeks after gene transfer. The predicted size of the PCR and RT-PCR products is 1003 bp. $\boldsymbol{b}-\boldsymbol{e}$, In situ hybridization was performed on rats killed after visual testing. The digoxigenin-containing hybridization probe was visualized using an alkaline phosphatase-conjugated anti-digoxigenin antibody and the alkaline phosphatase reaction (black). Sections were counterstained with methyl green, which stains nuclei. $\boldsymbol{b}, \boldsymbol{c}, A$ rat that received $\operatorname{Pkc} \Delta$ : POR cortex $(\boldsymbol{b})$ and entorhinal cortex (c). Filled arrows, Hybridization signal; open arrows, cell nuclei. $\boldsymbol{d}$, A no-surgery rat, POR cortex. $\boldsymbol{e}$, No hybridization probe, a rat that received Pkc $\Delta, P O R$ cortex (section proximal to that in $\boldsymbol{b}$ ). $\boldsymbol{f}, \mathrm{X}$-gal-positive cells in POR cortex in a rat killed after visual testing. $\boldsymbol{g}$-i, Coexpression of $\beta$-gal and Pkc $\Delta$ in POR cortex in a rat killed after visual testing: $\beta$-gal-IR $(\boldsymbol{g})$, flag-IR (h), merged ( $\boldsymbol{i}$. Arrows, Costained cells. $\boldsymbol{j}-\boldsymbol{I}, \boldsymbol{\beta}$-gal is expressed in POR cortex neurons in a rat killed after visual testing: $\beta$-gal-IR $(\boldsymbol{j})$, NeuN-IR $(\boldsymbol{k})$, merged (I). Arrows, Costained cells; open arrowhead, NeuN-IR only. Scale bars: $\boldsymbol{b}$ (for $\boldsymbol{b}-\boldsymbol{e}, \boldsymbol{j}-\boldsymbol{I}), \boldsymbol{f}, \boldsymbol{g}$ (for $\boldsymbol{g}-\boldsymbol{i}), 25 \mu \mathrm{m}$.

gene transfer, $>80 \%$ of the cells that contained Pkc $\Delta$ were neurons, as shown by costaining for flag-IR and a neuronal marker (GAP-43-Ser41-P, detailed below).

The minimal side effects that were observed are unlikely to enhance learning. There were minimal cytopathic effects and cell

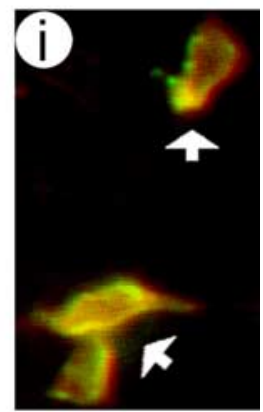

infiltration at the injection site, consistent with previous reports (Fraefel et al., 1996, their Fig. 5 and Table 2) (supplemental data, available at www.jneurosci. org as supplemental material). No brain tumors or gross behavioral abnormalities were observed. None of the rats that received Pkc $\Delta$ (or control vectors) displayed any behaviors that would suggest seizure activity. Also, although seizures induce c-fos, rats that received Pkc $\Delta$ and no visual testing contained only very low numbers of c-fos-immunoreactive cells in POR cortex (detailed below).

\section{Pkc $\Delta$ activated PKC pathways in POR} cortex during the time of visual testing We investigated the effects of Pkc $\Delta$ on the phosphorylation state of five different PKC substrates in POR cortex neurons. We used phospho-specific antibodies to examine the prevalence of specific phospho-proteins in $\mathrm{Pkc} \Delta$ - or Pkc $\Delta \mathrm{GG}$ containing cells or in unaffected neurons. In rats killed at 3 weeks after gene transfer, $P k c \Delta$-containing cells were identified using an anti-flag antibody, and these sections were costained with an antibody against a specific phospho-protein. $\mathrm{Pkc} \Delta$ containing cells showed high levels of costaining for two phospho-proteins that play critical roles in neurotransmitter release, GAP-43-Ser41-P (Fig. 4a-c) and dynamin-Ser795-P (supplemental Fig. S1 $a-c$, available at www.jneurosci.org as supplemental material). $\mathrm{Pkc} \Delta$-containing cells also showed high levels of costaining for the phosphorylated forms of two receptors that are essential for glutamatergic neurotransmission and learning, AMPA receptor GluR2 subunit-Ser880-P (supplemental Fig. S2a-c, available at www. jneurosci.org as supplemental material) and NMDA receptor NR1 subunitSer896-P (supplemental Fig. S3a-c, available at www.jneurosci.org as supplemental material). Additionally, $\operatorname{Pkc} \Delta$-containing cells showed high levels of costaining for a phospho-protein involved in signal transduction, MARCKS-Ser159/163-P (supplemental Fig. S4a-c, available at www. jneurosci.org as supplemental material). In contrast, Pkc $\Delta \mathrm{GG}$-containing cells, or neurons in no-surgery rats (identified using an anti-NeuN antibody), showed only low levels of costaining for each of these five phospho-proteins (for GAP-43Ser41-P, see Fig. $4 d-i$ ) (for the other four phospho-proteins, see supplemental Figs. S1-S4, $d-i)$. Cell counts established that Pkc $\Delta$, but not Pkc $\Delta$ GG, supported 240 $1140 \%$ increases in costaining for each of these five phosphoproteins compared with neurons in no-surgery rats (Fig. $4 \mathrm{~m}$ ) (supplemental Table S2, available at www.jneurosci.org as sup- 
plemental material). $\operatorname{Pkc} \Delta$ likely increased phosphorylation of each of these substrates during the time of visual learning because similar increases were observed in rats killed at either $4 \mathrm{~d}$ or 3 weeks after gene transfer. These increases in phosphorylation state were likely attributable to direct phosphorylation by $\mathrm{Pkc} \Delta$ because each of these PKC phosphorylation sites is not known to be phosphorylated by other protein kinases. As an additional control, $\mathrm{Pkc} \Delta$ did not increase costaining for a phospho-protein that is not a PKC substrate, CaMKII-Thr286-P (Fig. 4m) (supplemental Fig. S5, Table S2, available at www.jneurosci.org as supplemental material); to verify this assay, no-surgery rats were treated with systemic clozapine, and neurons showed increased costaining for CaMKII-Thr286-P.

Next, we determined the maximum potential level of costaining for each phosphoprotein by measuring the percentages of neurons that contain each protein independent of phosphorylation. Neurons in no-surgery rats were costained for each protein independent of phosphorylation, and costaining was observed using four of the antibodies (for GAP-43, see Fig. 4j-l) (for dynamin, AMPA GluR2, and NMDA NR1, see supplemental Figs. S1-S3, $j-l$, available at www.jneurosci.org as supplemental material); MARCKS was detected in a dense neuropil that obscured NeuN costaining (data not shown). Cell counts showed that $\mathrm{Pkc} \Delta$ supported levels of costaining for phospho-GAP-43, phospho-dynamin, phospho-AMPA receptors, and phospho-NMDA receptors that approached the maximum potential levels (Fig. 4m) (supplemental Table S2, available at www.jneurosci.org as supplemental material).

Additionally, we used Western analysis to confirm that Pkc $\Delta$ increased phosphorylation of dynamin. We killed rats at $4 \mathrm{~d}$ after gene transfer, prepared protein extracts from tissue proximal to the injection sites, and probed Western blots with antibodies that recognize either phosphodynamin (Fig. $4 n$ ) or dynamin independent of phosphorylation (Fig. 4o). Densitometry scans of the blots showed that $P k c \Delta$, but not $P k c \Delta G G$, increased the levels of phospho-dynamin compared with the levels found in no-surgery rats (Pkc $\Delta$ /no-surgery, $2.4 \pm 0.5$; Pkc $\Delta \mathrm{GG} /$ no-surgery, $0.9 \pm 0.2$; mean $\pm \mathrm{SEM} ; p<$ $0.05, t$ test). Pkc $\Delta$ did not affect the levels of dynamin protein ( $\mathrm{Pkc} \Delta /$ no-surgery, $1.1 \pm 0.1 ; \mathrm{Pkc} \Delta \mathrm{GG} /$ no-surgery, $0.9 \pm 0.1$; $p>0.05)$.

Because activation of PKC increases
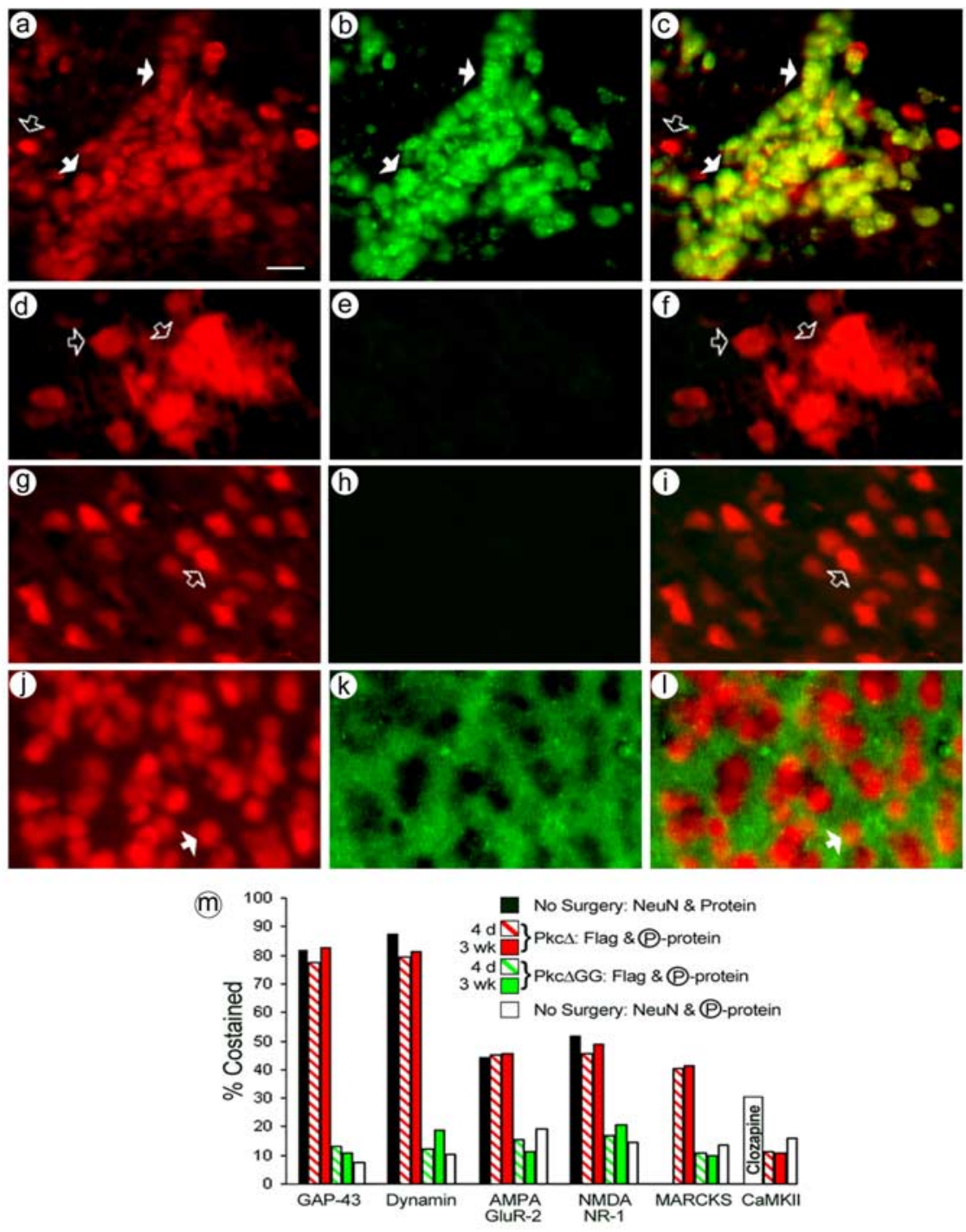

(n)
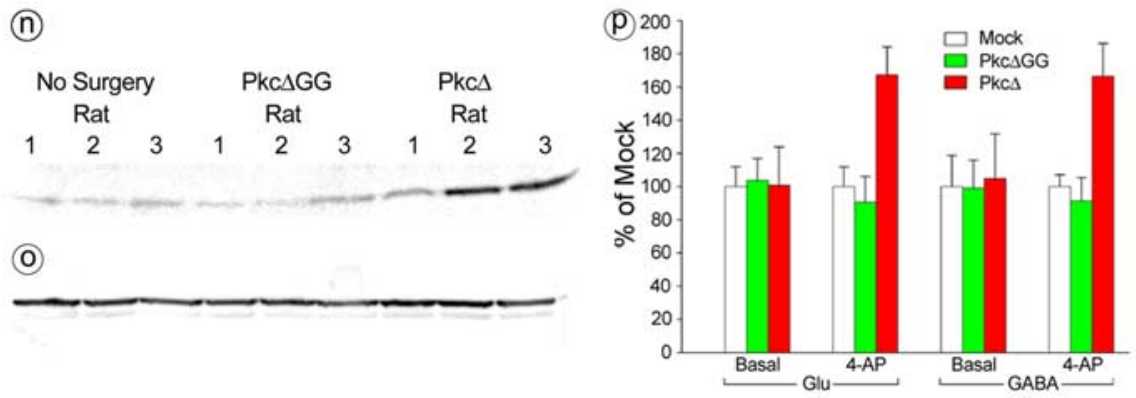

Figure 4. Pkc $\Delta$ increased phosphorylation of five PKC substrates in POR cortex cells, and Pkc $\Delta$ supported activationdependent increases in neurotransmitter release from cultured temporal cortex cells. $\boldsymbol{a}-\mathbf{I}$, Pkc $\Delta$ increased costaining for phosphorylated GAP-43 in POR cortex neurons, in a rat killed at 3 weeks after gene transfer. $\boldsymbol{a}-\boldsymbol{c}, \operatorname{Pkc} \Delta$ phosphorylated GAP-43: flag-IR $(\boldsymbol{a})$, GAP-43-Ser41-P-IR (b), merged (c). Filled arrows, Costained cells; open arrows, flag-IR only. $\boldsymbol{d}-\boldsymbol{f}$, Pkc $\Delta \mathrm{GG}$ did not phosphorylate GAP-43: flag-IR (d), GAP-43-Ser41-P-IR (e), merged $(\boldsymbol{f}) . \boldsymbol{g}$ - $\boldsymbol{i}$, Neurons in no-surgery rats contained low levels of phosphorylated GAP-43: NeuN-IR $(\boldsymbol{g})$, GAP-43-Ser41-P-IR $(\boldsymbol{h})$, merged $(\boldsymbol{i})$. $\boldsymbol{j}-\boldsymbol{I}$, Neurons in no-surgery rats contained GAP-43 protein: NeuN-IR $(\boldsymbol{j})$, GAP-43-IR $(\boldsymbol{k})$, merged $(\boldsymbol{I}) \cdot \boldsymbol{m}$, The percentage of costaining for Pkc $\Delta$ and specific phospho-proteins and controls; $100-400$ cells were counted for each condition. $n$, Western blot analysis showed that Pkc $\Delta$, but not Pkc $\Delta G G$, increased the levels of dynamin-Ser795-P compared with the levels in no-surgery rats. $\boldsymbol{0}$, Western blot analysis showed that $\mathrm{Pkc} \Delta$ did not alter the levels of dynamin protein (independent of phosphorylation) compared with the levels in either $\operatorname{Pkc} \Delta \mathrm{GG}$ or no-surgery rats. $\boldsymbol{p}$, $\mathrm{Pkc} \Delta$, but not $\mathrm{Pkc} \Delta \mathrm{GG}$, supported increases in the 4-AP-dependent release of Glu and GABA from cultured temporal cortex cells compared with mock infection (mean \pm SEM). Each condition was in triplicate, and the experiment was repeated twice ( 6 wells per condition total). Scale bar: (in $\boldsymbol{a}) \boldsymbol{a}-\mathbf{I}, 25 \mu \mathrm{m}$. 
neurotransmitter release (Nichols et al., 1987; Waters and Smith, 2000), we examined the effects of $\mathrm{Pkc} \Delta$ on neurotransmitter release from cultured temporal cortex neurons. We infected temporal cortex cells in dissociated cultures and, $1 \mathrm{~d}$ later, measured release of preloaded, radiolabeled $\left[{ }^{14} \mathrm{C}\right] \mathrm{Glu}$ and $\left[{ }^{3} \mathrm{H}\right] \mathrm{GABA}$. Pkc $\Delta$ did not affect basal efflux (low $\mathrm{K}^{+}$) of Glu or GABA compared with the controls ( $\mathrm{Pkc} \Delta \mathrm{GG}$ or mock infection, $p>0.05$, ANOVAs) (Fig. 4p). We mimicked activation-dependent conditions by blocking specific voltage-gated potassium channels with 4-AP. Of note, $\mathrm{Pkc} \Delta$, but not $\mathrm{Pkc} \Delta \mathrm{GG}$, supported increases in the 4-AP-dependent release of Glu and GABA compared with mock infection (Fig. 4p) [Pkc $\Delta$ vs Pkc $\Delta$ GG or mock, $p<0.01$ (Glu) or $p<0.05$ (GABA); Pkc $\Delta$ GG vs mock, $p>0.05$ (Glu or GABA)]. The 4-AP-dependent release of Glu and GABA was $\mathrm{Ca}^{2+}$ dependent in each condition (data not shown; $p>0.05$ ). Thus, Pkc $\Delta$ increased phosphorylation of two proteins that play critical roles in neurotransmitter release, GAP-43 and dynamin, and Pkc $\Delta$ supported activation-dependent increases in neurotransmitter release from both cultured sympathetic neurons (Song et al., 1998, their Table 3) and cultured temporal cortex neurons.

\section{Pkc $\Delta$ in POR cortex neurons enhanced visual object learning}

Rats were tested on simultaneous visual object discriminations using a computer-controlled touchscreen apparatus. For each trial, the rats pressed a lever to obtain an object set and pressed a touchscreen to choose an object (Cook et al., 2004, their Methods). To ensure uniform testing conditions, each apparatus was enclosed in a light-proof, sound-attenuating chamber. Throughout the behavioral testing, the rats were identified by a code that contained no information about their gene transfer condition.

Visual learning was evaluated after activation of PKC pathways in POR cortex neurons. In the experimental protocol (Fig. $5 a)$, rats were first trained to discriminate between horizontal versus vertical bars ( $\equiv$ vs \|\| ), and, after gene transfer, the rats were retested on this orientation discrimination. There were no significant differences in accuracy between the groups on this orientation discrimination, before or after gene transfer, in any experiment (Fig. 5b,c) ( $p>0.05$, ANOVAs). The rats were then trained on a new discrimination ( $\square$ vs + ), after which histological analyses were performed. Four independent experiments were performed. Each experiment contained three groups: (1) $\mathrm{Pkc} \Delta$ in POR cortex, (2) a vector system control group (either $\beta$-gal only or $\beta$-gal and $\mathrm{Pkc} \Delta \mathrm{GG}$ ), and (3) a no gene transfer control group [vehicle alone (PBS) or no surgery] (supplemental Table S3, available at www.jneurosci.org as supplemental material). In the first experiment, the rats that received $\mathrm{Pkc} \Delta$ learned the new object set $(\square$ vs + ) to a significantly higher level of accuracy than the different controls (Fig. 5b) (sessions 6-10, $p<$ 0.001, ANOVA; statistical comparisons used the last five sessions because most of the learning was completed by sessions 5-6). The $\mathrm{Pkc} \Delta$ group also required fewer sessions to reach $75 \%$ correct compared with the control group [second session $\geq 75 \%$ : Pkc $\Delta$, $5.0 \pm 0.60$ (mean \pm SEM); control ( $\beta$-gal and PBS), $7.2 \pm 0.61$; $p<0.05]$. In three additional experiments, the rats that received $\operatorname{Pkc} \Delta$ also showed higher levels of accuracy compared with the controls (data not shown) [experiment 2, sessions 5-9, $p<0.05$ (rats inadvertently killed after session 9); experiment 3, sessions $6-10, p<0.05$; experiment 4 , sessions $6-10, p=0.068$; but sessions $6-9, p<0.04$; and sessions $4-10, p<0.03$ ].

To isolate performance within individual sessions, we examined the performance of all of the rats from the four experiments, using a series of separate ANOVAs (Fig. $5 c$ ). For each of sessions $6,7,8,9$, and 10 , we found no significant differences between the

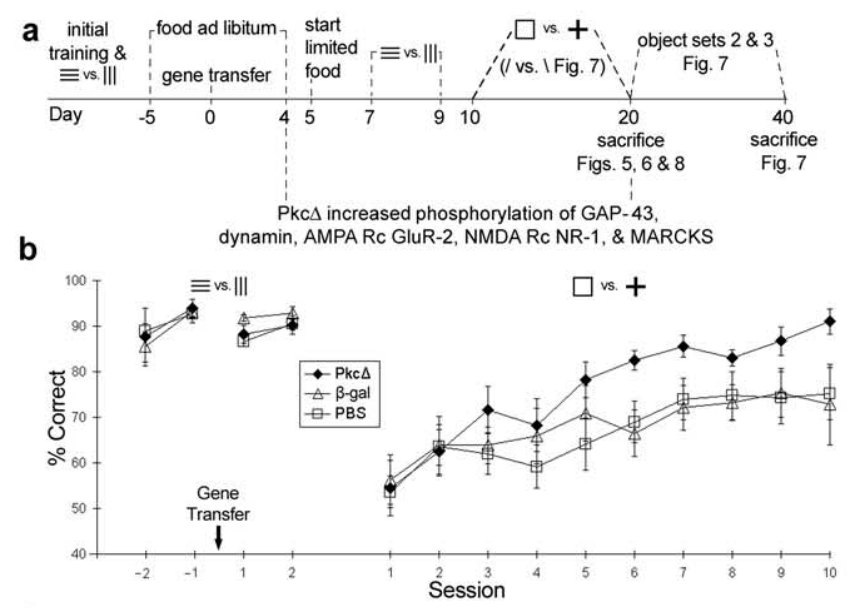

C

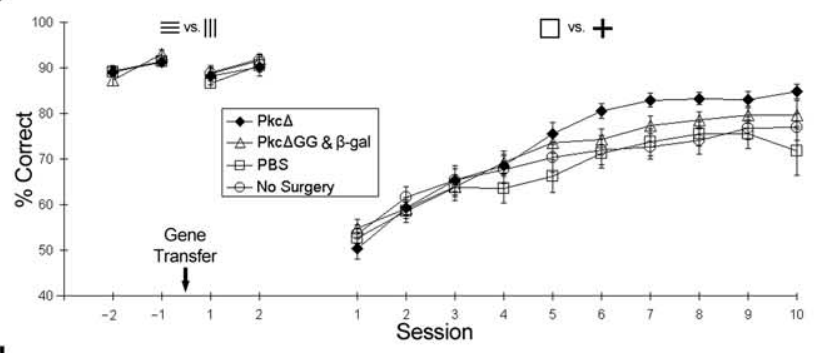

d

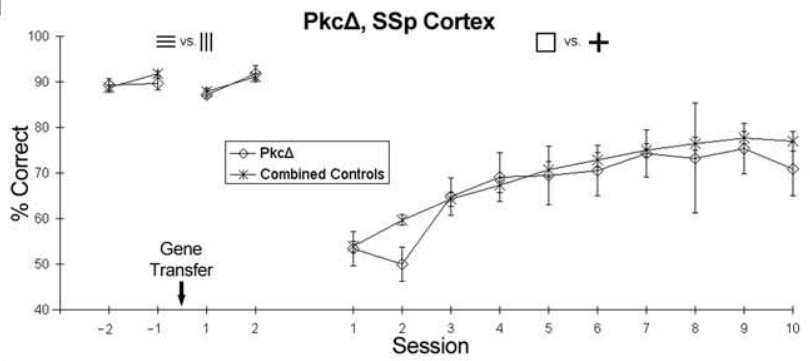

e

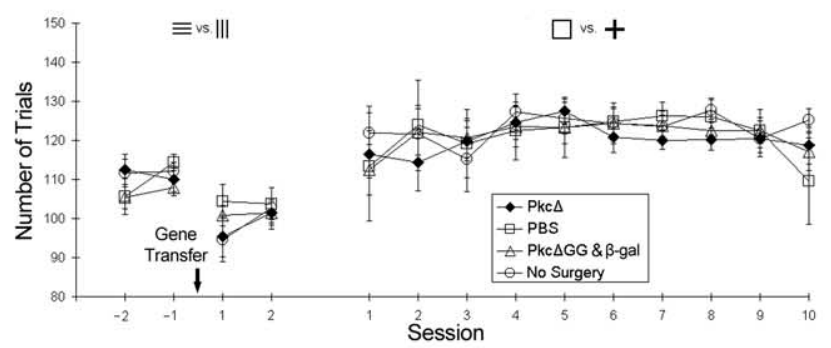

Figure 5. Rats that received Pkc $\Delta$ in POR cortex displayed enhanced performance on a new object set ( $\square$ vs + ). $\boldsymbol{a}$, A time line showing the experimental design. $\boldsymbol{b}$, In one experiment, the performance on $\equiv$ versus \|\| , before or after gene transfer, was similar for the rats in the different groups (mean \pm SEM). In contrast, the rats that received Pkc $\Delta$ exhibited enhanced performance on a new object set, $\square$ versus + (mean \pm SEM; Pkc $\Delta, n=8$ rats; $\beta$-gal, $n=11$ rats; PBS, $n=9$ rats). $c$, The performance of the rats from four independent experiments [Pkc $\Delta, n=28$ rats; vector system controls, $n=43$ rats; (Pkc $\Delta$ GG plus $\beta$-gal, $n=21$ rats; $\beta$-gal only, $n=22$ rats; these subgroups was virtually indistinguishable); PBS, $n=25$ rats; no surgery, $n=27$ rats]. $\boldsymbol{d}$, Rats that received Pkc $\Delta$ in SSp cortex displayed similar performance on $\square$ versus + compared with the rats in the combined control group (vector system controls, $\mathrm{PBS}$, and no surgery; $\mathrm{Pkc} \Delta / \mathrm{SSp}$ cortex,$n=9$ rats; 0 ther rats from $\boldsymbol{c}$ ). $\boldsymbol{e}$, The numbers of trials per session completed by the rats in each group (mean \pm SEM).

no-surgery group and the other control groups (no surgery vs either PBS or Pkc $\Delta$ GG plus $\beta$-gal; $p>0.05$ ). Of most importance, we found that the rats that received $\operatorname{Pkc} \Delta$ displayed significantly higher accuracies during each of sessions 6,7 , and 8 compared with the combined control group (no surgery, PBS, and Pkc $\Delta$ GG 
plus $\beta$-gal; $p<0.05$ ), and a higher accuracy that approached significance for session $9(p=0.096)$. The accuracy exhibited by the rats in the control groups was comparable with that in other touchscreen paradigms (Markham et al., 1996). There were small variations in the performance of the control groups between the four experiments, resulting in modestly larger differences between the control groups for the combined four experiments (Fig. 5c) than for each individual experiment (such as Fig. 5b). Despite this modest variation in the control groups between experiments, $\mathrm{Pkc} \Delta$ consistently increased accuracy $5-15 \%$ in the combined four experiments (Fig. $5 c$, sessions 6-10).

As an additional control, delivery of $\mathrm{Pkc} \Delta$ into cells in a cortical area not involved in visual learning, SSp cortex, did not enhance learning relative to controls and was significantly poorer than $\mathrm{Pkc} \Delta$ in POR cortex (Fig. 5d) (sessions 6-10; Pkc $\Delta$ in SSp cortex vs combined controls, $p>$ $0.05 ; \mathrm{Pkc} \Delta$ in SSp cortex vs Pkc $\Delta$ in POR cortex, $p \leq 0.001)$. Also, the enhanced performance exhibited by the Pkc $\Delta$ in POR cortex group was not attributable to the completion of more trials because all of the groups completed similar numbers of trials throughout the testing (Fig. 5e) $(p>$ 0.05).

We established that the activity of NMDA receptors is required for this discrimination because systemic injection of dizocilpine reduced performance to chance in rats that received $\mathrm{Pkc} \Delta$ in POR cortex [dizocilpine, $52 \pm 6 \%$ correct (mean \pm SEM); next session, $84 \pm 2 \% ; p<0.001$ ( $t$ test); systemic PBS, $87 \pm 2 \%$; next session, $87 \pm 2 \%$; $p>0.05$ ]. Injection of dizocilpine did not significantly affect motor activity (dizocilpine, $111 \pm 9$ trials; next session, $125 \pm 4$ trials; systemic PBS, $118 \pm 8$ trials; next session, $116 \pm 12$ trials).

To confirm that the POR cortex neurons that contained Pkc $\Delta$ supported the enhanced learning, we investigated the relationship between the numbers of transfected cells and the learning in individual rats. Two planned comparisons were evaluated using Pearson's product moment correlations. (Although we used this linear regression method to establish correlations, we recognize that complex nonlinear mechanisms may influence how the numbers and types of transfected cells affect performance.) We examined the learning rate by evaluating the number of sessions required to reach two sessions $\geq 75 \%$ correct. We examined steady-state accuracy by evaluating the average percentage correct for sessions 6-10. For the rats that received $\mathrm{Pkc} \Delta$ in $\mathrm{POR}$ cortex, the numbers of transfected cells correlated with both the learning rate (Fig. 6a) and the steady-state accuracy (Fig. $6 d$ ), but the rats that received either Pkc $\Delta$ GG in POR cortex (Fig. 6b,e) or $\mathrm{Pkc} \Delta$ in SSp cortex (Fig. $6 c, f$ ) did not exhibit these correlations (learning rates: $\mathrm{Pkc} \Delta$ in POR cortex, $r_{(11)}=-0.67, p<0.05$; $\mathrm{Pkc} \Delta \mathrm{GG}$ in POR cortex, $r_{(12)}=-0.10, p>0.05$; Pkc $\Delta$ in SSp cortex, $r_{(9)}=-0.23, p>0.05$; steady-state accuracies: Pkc $\Delta$ in POR cortex, $r_{(11)}=0.86, p<0.01$; Pkc $\Delta$ GG in POR cortex, $r_{(12)}=-0.18, p>0.05 ;$ Pkc $\Delta$ in SSp cortex, $\left.r_{(9)}=-0.094, p>0.05\right)$.
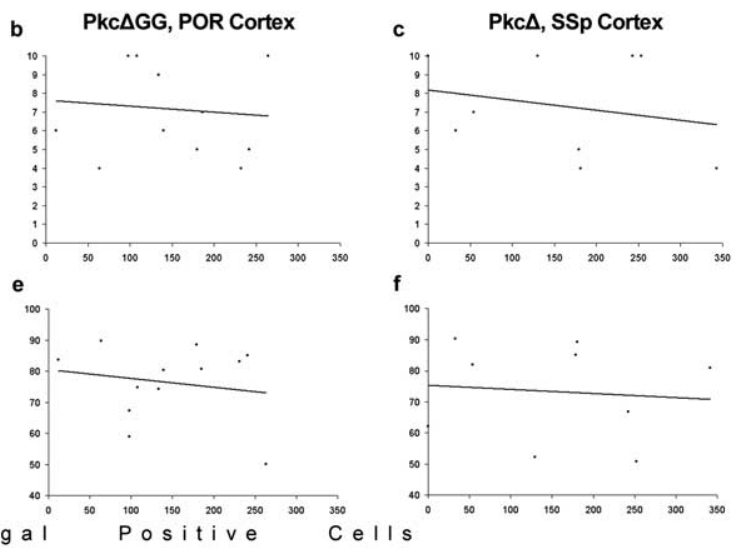

Figure 6. For individual rats that received $\mathrm{Pkc} \Delta$ in POR cortex, the numbers of transfected cells was correlated with perforrats in the different groups exhibited similar performances on an object set that was learned in less than one session ( $\lrcorner$ vs $\top$ ) or on an object set that was not acquired ( $\lrcorner$ vs $\perp$ ).

Thus, activation of PKC pathways in POR cortex neurons enhanced learning (Fig. 5), and the number of transfected neurons correlated with both the learning rate and steady-state accuracy (Fig. 6).

\section{Learning of object sets of varying difficulty}

We next examined how the level of difficulty of an object set modified the effects of Pkc $\Delta$ on learning. Again, there were no differences between the different groups on the retested orientation discrimination (Fig. 7a) (三 vs $\| ; p>0.05$ ). The rats that received Pkc $\Delta$ displayed enhanced accuracy on / versus $\backslash$ compared with the control groups (Fig. 7a) (sessions 6-10; Pkc $\Delta$ vs either Pkc $\Delta \mathrm{GG}$ or no surgery, $p<0.01$; Pkc $\Delta \mathrm{GG}$ vs no surgery, $p>0.05)$. The two object sets / versus $\backslash$ and $\square$ versus + appear to be of similar difficulty, because most rats learned these object sets in four to six sessions. There were small differences in the learning of these two image sets (compare Figs. 5b, 7a), but these differences were not statistically significant $[\operatorname{Pkc} \Delta \square$ vs + (Fig. $5 b$ ) compared with $\operatorname{Pkc} \Delta /$ vs $\backslash p>0.05$; control groups $\square$ vs + (Fig. $5 b)$ compared with control groups / vs $\backslash p>0.05]$. A second phase tested these rats on an easier object set that was learned in less than one session, and there were no differences between the groups (Fig. $7 b$, top) ( $p>0.05)$. Conversely, rats that received $\mathrm{Pkc} \Delta$ failed to learn a difficult object set that the rats in a control group also failed to learn (Fig. $7 b$, bottom). Thus, five experiments (Figs. 5, 7) (supplemental Table S3, available at www.jneurosci.org as supplemental material) showed that Pkc $\Delta$ enhanced the learning of two different object sets of similar, intermediate difficulty. 


\section{$\operatorname{Pkc} \Delta$ potentiated the activity of specific POR cortex circuits during the learning}

We investigated the levels of neuronal activity in neurons proximal to the transfected neurons. We focused on the sustained neuronal activity produced by accurate visual discrimination rather than changes in synaptic plasticity during the initial learning, by examining the rats after session 10 on $\square$ versus + . To examine the activity of many neurons located proximal to the transfected neurons, we measured induction of three IE genes, c-fos, Arc, and Zif268. Visual learning increases c-fosimmunoreactive cell density in POR cortex (Wan et al., 1999); Arc-IR is a marker for active synapses (Lyford et al., 1995); and Zif268 is required for late LTP, long-term memory, and reconsolidation (Bozon et al., 2003). Thus, any changes observed in all three assays were likely caused by sustained neuronal activity rather than by coincidental induction of all three IE genes by independent mechanisms unrelated to neuronal activity.

Rats were killed immediately after session 10, neuronal activity was assayed using c-fos-IR, or Arc-IR, or Zif268-IR, and the transfected cells were identified using X-gal staining. Control rats that received Pkc $\Delta \mathrm{GG} / \square$ versus + contained relatively uniform levels of c-fos-IR and $A r c$-IR at different distances from the injection site (Fig. $8 a, d$ ). In contrast, experimental rats that received $\mathrm{Pkc} \Delta / \square$ versus + contained elevated levels of c-fos-IR and Arc-IR proximal to the injection sites (Fig. $8 b, e$ ). High-power views showed that the c-fos-IR was localized to nuclei, and the Arc-IR was localized to processes (Fig. $8 c, f$ ). Additionally, sections from a rat that received $\mathrm{Pkc} \Delta / \square$ versus + were costained for $\mathrm{c}$-fos-IR and Zif268-IR, and high-power views showed that c-fos-IR and Zif268-IR were present in many of the same cells (Fig. $8 g-i$ ).

We used stereology to quantify c-fos-immunoreactive cell densities and $A r c$-immunoreactive densities in column-shaped volumes, extending from the cortical surface to the white matter, at different distances from the injection site. A photomicrograph of the stereological counting contours (Fig. 8j) shows that most of the transfected cells were contained within an $\sim 200-\mu \mathrm{m}$-wide volume [volume labels: injection site dorsal (I-D) or injection site ventral $(\mathrm{I}-\mathrm{V})]$. We also counted three volumes at increasing distances from the injection site in either the dorsal or ventral directions (volume labels: dorsal or ventral 1, 2, or 3 (abbreviated D-1 through $\mathrm{V}-3)$ ].

Of note, rats that received $\operatorname{Pkc} \Delta / \square$ versus + contained higher c-fos-immunoreactive cell density $(270 \%)$ and Arcimmunoreactive density (250\%) in $\sim 200$ - $\mu \mathrm{m}$-wide and $\sim 600$ $\mu \mathrm{m}$-wide volumes, respectively, centered on the injection site compared with the other volumes (Fig. $8 k, l)$ (c-fos-IR: $\Sigma$ I-D,I-V volumes compared with $\Sigma \mathrm{D} 1-3, \mathrm{~V} 1-3$ volumes, $p<0.001$; $\Sigma \mathrm{D} 1-3$ compared with $\Sigma \mathrm{V} 1-3, p>0.05 ;$ Arc-IR: $\Sigma \mathrm{V}-1, \mathrm{I}, \mathrm{D}-1$ compared with $\Sigma \mathrm{D} 2-4, \mathrm{~V} 2-4, p<0.005 ; \Sigma \mathrm{D} 2-4$ compared with $\Sigma \mathrm{V} 2-4, p>0.05)$. The wider $(\sim 600 \mu \mathrm{m})$ volume of increased Arc-immunoreactive density, a marker for active synapses (Lyford et al., 1995), may be attributable to axon collaterals from neurons within the $\sim 200$ - $\mu \mathrm{m}$-wide volume of increased c-fosimmunoreactive cell density. These increases in neuronal activity required learning a new object set ( $\square$ vs + ), because these increases were not observed in rats that received $\operatorname{Pkc} \Delta$ and retesting after gene transfer on the initial discrimination (三vs || $\mid$ ) (Fig. 8k,l) (c-fos-IR: Pkc $\Delta / \square$ vs $+\sum \mathrm{I}-\mathrm{D}, \mathrm{I}-\mathrm{V}$ compared with $\mathrm{Pkc} \Delta / \equiv$ vs || $\mid, p<0.001 ; A r c-$ IR: Pkc $\Delta / \square$ vs $+\sum \mathrm{V}$-1,I,D-1 compared with $\mathrm{Pkc} \Delta / \equiv \mathrm{vs}\|\|, p<0.001)$.

We compared the $c$-fos-immunoreactive cell densities and the $A r c$-immunoreactive densities in the $\operatorname{Pkc} \Delta / \square$ versus + group to the densities in control groups that were tested on $\square$ versus + . In
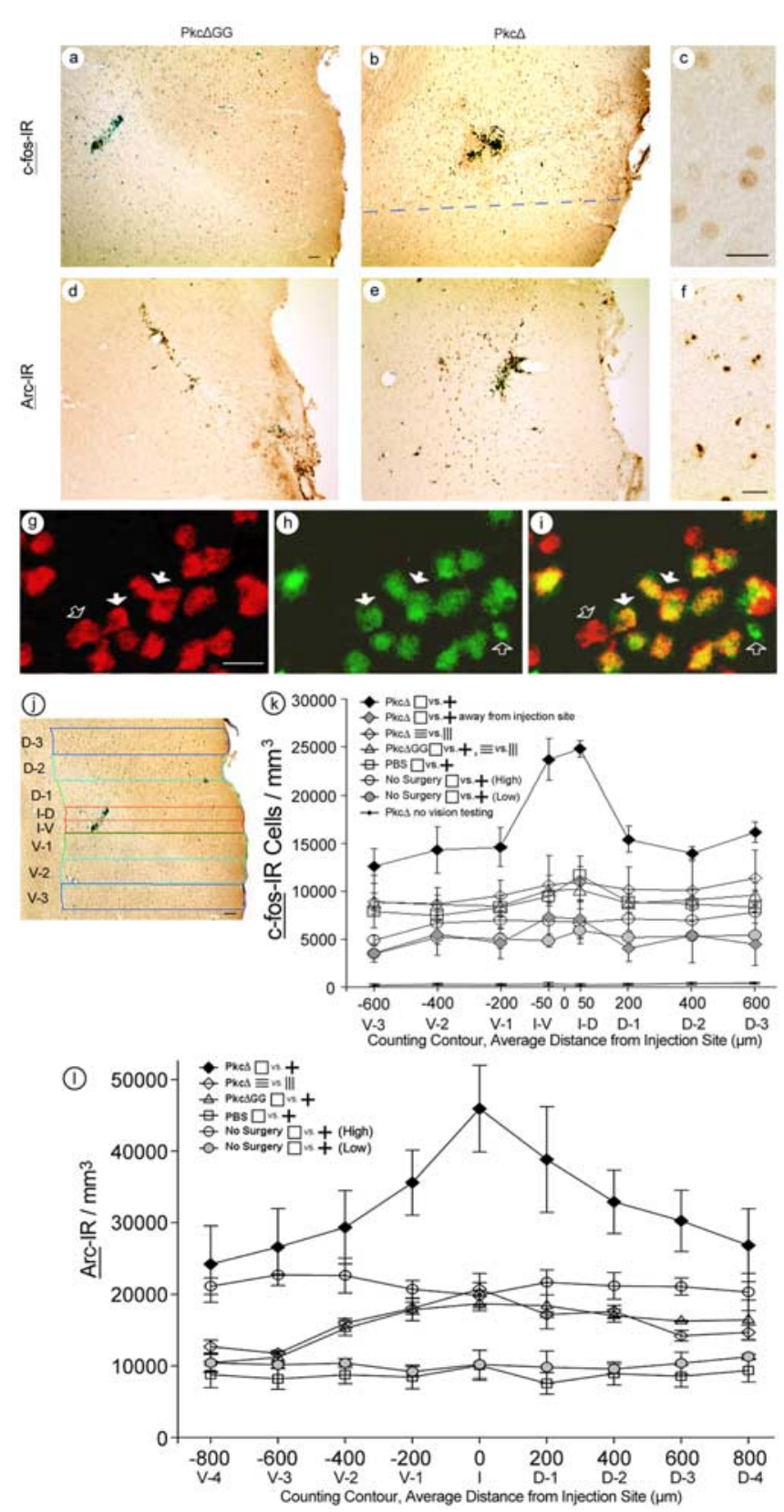

Figure 8. Neuronal activity was increased in neurons proximal to the $\operatorname{Pkc} \Delta$-containing neurons in rats that were tested on $\square$ versus $+. \boldsymbol{a}-\boldsymbol{f}, \mathrm{X}$-gal staining and either c-fos-IR or Arc-IR from rats killed after session 10 on $\square$ versus $+. \boldsymbol{a}-\boldsymbol{c}, \mathrm{X}$-gal and c-fos-IR:Pkc $\Delta \mathrm{GG}(\boldsymbol{a})$ and Pkc $\Delta$ (b). The dashed line approximately separates an area proximal to the injection site that contains elevated c-fos-immunoreactive cell density (above) from an area with lower c-fosimmunoreactive cell density. $c$, A high-power view of c-fos-IR (an area proximal to the injection site in $\boldsymbol{b}$ is shown). $\boldsymbol{d}-\boldsymbol{f}$, X-gal and $\operatorname{Arc}-\mathrm{IR}$ : $\operatorname{Pkc} \Delta \mathrm{GG}(\boldsymbol{d})$ and $\mathrm{Pkc} \Delta(\boldsymbol{e})$; contains higher $\operatorname{Arc}-\mathrm{IR}$ density than the $P k c \Delta G G$ control.f, Pkc $\Delta$, a high-power view. $\boldsymbol{g}-\boldsymbol{i}$, Coinduction of c-fos-IR and Zif268-IR from a rat killed after session 10 on $\square$ versus + : c-fos-IR (g), Zif268-IR (h), merged (i). Filled arrows, Costained cells; open arrows, singly stained cells. $j$, The contours used for the stereological counts of c-fos-immunoreactive cells. I-D and I-V are $100 \mu \mathrm{m}$ wide; D1-D3 and V1-V3 are $200 \mu \mathrm{m}$ wide. Each contour was adjusted to extend from the dorsal surface to the white matter of each section. $\boldsymbol{k}, \boldsymbol{I}$, The densities of c-fos-immunoreactive cells $(\boldsymbol{k})$ or $\operatorname{Arc}-\operatorname{IR}(\boldsymbol{I})$ in volumes centered at increasing distances from the injection site, for the different groups: c-fosIR: Pkc $\Delta / \square$ versus,$+ n=7$ rats; Pkc $\Delta / \square$ versus + away-from-injection-site, $n=4$ rats; $\operatorname{Pkc} \Delta / \equiv$ versus \|\|$, n=3$ rats (killed after session 9); $\operatorname{Pkc} \Delta \mathrm{GG} / \square$ versus,$+ \equiv$ versus \|\| , $n=9$ rats ( $\square$ vs,$+ n=6$ rats; $\equiv$ vs \|\|$, n=3$ rats; these two subgroups were similar); $\mathrm{PBS} / \square$ versus,$+ n=3$ rats; no-surgery/ $\square$ versus + (high or low), $n=3$ rats; Pkc $\Delta /$ no visual testing, $n=3$ rats; $\operatorname{Arc-IR:Pkc} \Delta / \square$ versus,$+ n=4$ rats; Pkc $\Delta / \equiv$ versus $\| \mid, n=3$ rats; Pkc $\Delta \mathrm{GG} / \square$ vs,$+ n=3$ rats; $\mathrm{PBS} / \square$ versus,$+ n=3$ rats; no-surgery $/ \square$ versus + (high or low), $n=3$ rats. Scale bars: $\boldsymbol{a}, \boldsymbol{b}, \boldsymbol{d}, \boldsymbol{e}, 50 \mu \mathrm{m} ; \boldsymbol{c}, \boldsymbol{f}, \boldsymbol{g}-\boldsymbol{i}, 25 \mu \mathrm{m} ; \boldsymbol{j}, 100 \mu \mathrm{m}$. 
no-surgery $/ \square$ versus + rats, c-fos-immunoreactive cell density and $A r c$-immunoreactive density displayed some variation within POR cortex; for each no-surgery rat, $\sim 10$ sections that contained POR cortex were examined for either c-fosimmunoreactive cell density or Arc-immunoreactive density, and two curves that represent the high and low for each density are shown (Fig. 8k,l). c-fos-immunoreactive cell density and Arcimmunoreactive density in the no-surgery/ $\square$ versus + (high) group is similar to, or greater than, each of the injection control conditions (Fig. 8k,l) [no-surgery/ $\square$ vs + (high) compared with $\operatorname{Pkc} \Delta \mathrm{GG} / \square$ vs,$+ \equiv$ vs $\|, \operatorname{PBS} / \square$ vs + , or $\operatorname{Pkc} \Delta / \equiv$ vs $\| \mid$ $c$-fos-IR, all volumes, $p>0.05$; Arc-IR, all volumes, $p<0.001]$. Of note, the increases in neuronal activity in the $\operatorname{Pkc} \Delta / \square$ versus + group required $\mathrm{Pkc} \Delta$, because these increases were not observed in rats that received each of the control conditions $/ \square$ versus + (Fig. $8 k, l$ ) (c-fos-IR: Pkc $\Delta / \square$ vs $+\sum \mathrm{I}-\mathrm{D}, \mathrm{I}-\mathrm{V}$ compared with each of Pkc $\Delta$ GG $/ \square$ vs,$+ \equiv$ vs $\| \mid$, PBS/ $\square$ vs + , or no-surgery/ $\square$ vs + (high or low), $p<0.001$; Arc-IR: Pkc $\Delta / \square$ vs $+\sum \mathrm{V}-1, \mathrm{I}, \mathrm{D}-1$ compared with each of the control groups, $p<0.001]$.

The increases in neuronal activity in the $\operatorname{Pkc} \Delta / \square$ versus + group were localized to the volumes that contained, or were proximal to, the injection site. In the $\operatorname{Pkc} \Delta / \square$ versus + group, sections distant from the injection site did not contain increased c-fos-immunoreactive cell density (Fig. $8 k$ ) $[\mathrm{Pkc} \Delta / \square$ vs + awayfrom-injection-site compared with no-surgery/ $\square$ vs + (low), all volumes, $p>0.05]$.

$\operatorname{Pkc} \Delta$ alone did not induce neuronal activity. Rats that received $\mathrm{Pkc} \Delta /$ no visual testing contained very low levels of $\mathrm{c}$-fosimmunoreactive cell density (Fig. $8 k$ ), and visual testing caused large increases in c-fos-immunoreactive cell density in all of the volumes examined, consistent with previous reports (Wan et al., 1999) $(\mathrm{Pkc} \Delta$ /no visual testing compared with each of the other groups, all volumes, $p<0.001)$. The $\mathrm{Pkc} \Delta /$ no visual testing control also showed that the surgery and gene transfer procedures did not increase c-fos-immunoreactive cell density.

To provide additional evidence that the changes in c-fosimmunoreactive cell density were caused by changes in neuronal activity, we determined the frequency of costaining for c-fos-IR and $Z$ if 268 -IR. In $\mathrm{Pkc} \Delta / \square$ versus + rats, cell counts showed that $84 \%$ of the positive cells contained both c-fos-IR and Zif268-IR (in I-D and I-V volumes, 456 costained cells, $42 c$-fos-IR only cells, and 46 Zif268-IR only cells).

\section{Discussion}

\section{POR cortex neurons potentiated by $\operatorname{Pkc} \Delta$ enhanced learning}

The Pkc $\Delta$ in POR cortex condition enhanced visual object learning. In five experiments, $\operatorname{Pkc} \Delta$ increased the learning rate and final accuracy for rats tested with two object sets of moderate difficulty. A Pkc $\Delta$ GG control condition lacking enzyme activity did not show this learning enhancement. Also, delivery of Pkc $\Delta$ into a cortical area not involved in visual learning failed to enhance learning. The numbers of $\mathrm{Pkc} \Delta$-containing POR cortex neurons positively correlated with both the learning rate and steady-state accuracy. These correlations were not observed in the controls.

The magnitude of enhanced learning appears modest. Similarly, transgenic mice overexpressing a specific NMDA receptor subunit displayed modest increases in performance on several paradigms (Tang et al., 1999). Pharmacological interventions that enhanced learning or memory also usually produced small increases in performance; for example, systemic opiate agonists supported small enhancements in working memory in the radial arm maze (Canli et al., 1990). The magnitude of enhanced learn- ing typically reported in the literature and, here, is smaller than the magnitude of decreased learning caused by lesions or knockouts. This is because meaningful improvements in learning capability support only modest increases in accuracy or other performance measures (Rumelhart et al., 1986; Dudai, 1989). The maximum possible level of performance is one reason for this difference; there is usually more space for decreased, than increased, performance. Moreover, learning processes probably map nonlinearly onto dependent variables such as accuracy. It is easier to increase performance early in training (e.g., from 50 to $60 \%$ ) than after a task is almost mastered (e.g., from 80 to $90 \%$ ). Because our control rats achieved $\sim 75 \%$ correct, a lesion that reduced learning to chance would cause an $\sim 25 \%$ decrease, whereas a $25 \%$ increase to $100 \%$ is unlikely.

The mere presence of $\mathrm{Pkc} \Delta$ did not enhance learning. Pkc $\Delta$ did not enhance accuracy with the object set acquired before gene transfer, suggesting that $\mathrm{Pkc} \Delta$ must be present during acquisition to modulate learning. $\operatorname{Pkc} \Delta$ did not enhance learning of an easy object set or enable learning of a difficult object set that control rats failed to learn. Thus, $\mathrm{Pkc} \Delta$ likely modifies existing learning mechanisms: easy discriminations may be learned by an efficient process that $\mathrm{Pkc} \Delta$ cannot improve; cognitively demanding discriminations may be learned by a suboptimal process that Pkc $\Delta$ can improve; and $\operatorname{Pkc} \Delta$ cannot support learning beyond the capabilities of normal rats.

More than $90 \%$ of the transfected POR cortex cells were neurons, approximately half glutamatergic and half GABAergic. Enhanced learning was likely not caused by the minimal numbers of either transfected modulatory neurons in POR cortex or transfected neurons in specific cortical areas with large projections to POR cortex. Subcortical modulatory circuits cannot account for enhanced learning; $\mathrm{Pkc} \Delta$ was not detected in any of the examined subcortical areas. Thus, the transfected glutamatergic and GABAergic neurons in POR cortex most likely supported the enhanced learning.

\section{Pkcs supported changes in neuronal physiology that could enhance learning}

Pkc $\Delta$ phosphorylated two PKC substrates that affect synaptic plasticity through presynaptic mechanisms. PKC-mediated phosphorylation of GAP-43 increases neurotransmitter release (Routtenberg, 1999) and enhances hippocampal LTP and learning (Routtenberg et al., 2000; Hulo et al., 2002). Dynamin is essential for synaptic vesicle recycling, and PKC-mediated phosphorylation of dynamin regulates this process (Robinson et al., 1993; Powell et al., 2000). Consistent with increased phosphorylation of two proteins that regulate release, $\operatorname{Pkc} \Delta$ supported increases in release from cultured sympathetic neurons (Song et al., 1998) and temporal cortex cells. Pharmacological activation of $\mathrm{PKC}$ increases release from neurons from throughout the nervous system (Nichols et al., 1987; Waters and Smith, 2000). Thus, $\mathrm{Pkc} \Delta$-mediated increases in phosphorylation of GAP-43 and dynamin, and activation-dependent release, might enhance learning. Specifically, neuronal activity associated with visual learning might increase release from $\mathrm{Pkc} \Delta$-containing neurons, enhancing learning.

Pkc $\Delta$ phosphorylated three postsynaptic PKC substrates that play critical roles in synaptic plasticity. Phosphorylation of AMPA receptor GluR2-Ser880 is required for LTD and alters its affinity for specific intracellular anchoring proteins (Chung et al., 2003; Seidenman et al., 2003). Phosphorylation of NMDA receptor NR1 by PKC disperses clustered receptors, presumably by disrupting interactions with specific anchoring proteins (Tingley 
et al., 1997), and alters NMDA currents (Zheng et al., 1999). MARCKS is phosphorylated by stimuli that induce LTP and synaptic plasticity (Ramakers et al., 1999). More generally, PKC inhibitors block LTP (Malenka and Nicoll, 1999), and constitutively active PKC $\zeta$ is necessary for maintenance of LTP (Ling et al., 2002). Thus, Pkc $\Delta$ phosphorylates specific glutamate receptor subunits that affect synaptic plasticity; altered activity of these subunits could enhance learning.

We did not directly measure changes in synaptic plasticity caused by $\operatorname{Pkc} \Delta$. It is difficult to identify the synapses of the small numbers of $\mathrm{Pkc} \Delta$-containing neurons for electrophysiological recordings. Direct measurements of synaptic plasticity seem more critical for transgenic mice/learning studies. In most transgenic mice/learning studies, gene expression is altered throughout the forebrain, or more widely, and electrophysiology provides the primary, correlative, evidence localizing learning to a specific forebrain area. In contrast, by using localized gene transfer, we established that $\mathrm{Pkc} \Delta$-containing glutamatergic and GABAergic POR cortex neurons supported enhanced learning, without directly measuring synaptic plasticity, a topic for future experiments.

\section{During learning, neuronal activity was increased in circuits containing transfected neurons}

Rats that received $\mathrm{Pkc} \Delta$ and learned the discrimination contained increases in c-fos-immunoreactive and $A r c$-immunoreactive densities in volumes containing, or near, the transfected neurons, compared with volumes distant from the transfected neurons in the same sections or volumes in sections distant from the injection site. Additionally, cells near the transfected neurons contained high levels of costaining for c-fos-IR and Zif268-IR. Increased IE gene expression was observed in three assays; it was likely caused by sustained neuronal activity, not by coincidental induction of three IE genes by mechanisms unrelated to neuronal activity. c-fos-immunoreactive and $A r c$-immunoreactive densities were not increased in rats that received $\mathrm{Pkc} \Delta$ and retesting on the object set learned before gene transfer. These increases were not observed in rats that learned $\square$ versus + without Pkc $\Delta$. Thus, increased activity required both $\mathrm{Pkc} \Delta$ and learning a new object set. This increased activity was closely associated with enhanced learning.

Although Pkc $\Delta$ was expressed in both excitatory and inhibitory neurons, these IE gene assays establish increased activity during the learning. Similarly, many transgenic mice studies alter gene expression in multiple types of neurons and affect activity and learning.

The localized increases in activity that occurred with learning are congruent with specific properties of neurons in monkey inferotemporal or perirhinal cortex. Columns of neurons in monkey inferotemporal cortex respond to similar objects (Fujita et al., 1992). After visual experience, proximal pairs of neurons in monkey perirhinal cortex exhibit similar firing properties, but distant pairs of neurons are uncorrelated (Erickson et al., 2000). Monkey perirhinal cortex neurons increase activity as an object becomes familiar (Holscher et al., 2003). In our system, because the volume of increased activity was only $200 \mu \mathrm{m}$ wide, it would be difficult to detect this increase with electrophysiology. In summary, our results suggest that, during learning, $\operatorname{Pkc} \Delta$-containing neurons potentiated activity in proximal neurons, and this increased activity contributed to enhanced learning.

\section{Localization of learning within a cortical area}

Our results are consistent with the postulate from neural network theory that activating a small fraction of the neurons in a circuit can potentiate that circuit (Rumelhart et al., 1986). Only a few hundred of the $\sim 110,000$ neurons in POR cortex (Rapp et al., 2002) contained $\mathrm{Pkc} \Delta$, a small percentage. However, these neurons were spatially grouped together, and the higher local concentration of transfected neurons potentiated specific circuits and enhanced learning. Thus, at least a portion of the learning was localized to circuits containing the transfected neurons. Our results support the central hypothesis of this study: specific circuits within a neocortical area can support learning.

The differing results on localization of learning obtained using gain-of-function or ablation/loss-of-function strategies are generally consistent with the logic of each strategy. The gain-offunction strategy used here localizes learning to a specific circuit because it potentiates the activity of that circuit in the presence of multiple circuits that could support the learning. Thus, learning can be localized to a specific circuit even in the presence of multiple circuits that could perform the task. In contrast, ablation/loss-of-function strategies must remove/inactivate all the circuits that can support the learning before deficits are observed. If multiple circuits within a cortical area can support the learning, then all of these circuits must be removed/inactivated before a learning deficit is observed. To obtain a deficit, an entire cortical area must likely be affected by an ablation/ loss-of-function intervention, consistent with many studies (Dudai, 1989).

There are implications from localizing learning to specific circuits within a cortical area. Our results suggest that multiple circuits in POR cortex can support visual learning because Pkc $\Delta$ was delivered into different groups of neurons, in different locations in POR cortex, in each rat (from variability in microinjection/gene transfer). Such plasticity is often postulated for many cortical association areas (Rumelhart et al., 1986; Dudai, 1989). If a representation of the object set is stored in the circuit containing the $\operatorname{Pkc} \Delta$-transfected neurons, then the number of objects sets that can be learned with enhanced accuracy may be finite; this number may reflect the circuit capacity, which can be calculated using neural network theories (Rumelhart et al., 1986).

\section{References}

Abeliovich A, Paylor R, Chen C, Kim JJ, Wehner JM, Tonegawa S (1993) PKC gamma mutant mice exhibit mild deficits in spatial and contextual learning. Cell 75:1263-1271.

Bozon B, Davis S, Laroche S (2003) A requirement for the immediate early gene zif268 in reconsolidation of recognition memory after retrieval. Neuron 40:695-701.

Burwell RD, Amaral DG (1998a) Cortical afferents of the perirhinal, postrhinal, and entorhinal cortices of the rat. J Comp Neurol 398:179-205.

Burwell RD, Amaral DG (1998b) Perirhinal and postrhinal cortices of the rat: interconnectivity and connections with the entorhinal cortex. J Comp Neurol 391:293-321.

Bussey TJ, Muir JL, Aggleton JP (1999) Functionally dissociating aspects of event memory: the effects of combined perirhinal and postrhinal cortex lesions on object and place memory in the rat. J Neurosci 19:495-502.

Canli T, Cook RG, Miczek KA (1990) Opiate antagonists enhance the working memory of rats in the radial maze. Pharmacol Biochem Behav 36:521-525.

Chen C, Kano M, Abeliovich A, Chen L, Bao S, Kim JJ, Hashimoto K, Thompson RF, Tonegawa S (1995) Impaired motor coordination correlates with persistent multiple climbing fiber innervation in PKC gamma mutant mice. Cell 83:1233-1242.

Chung HJ, Steinberg JP, Huganir RL, Linden DJ (2003) Requirement of 
AMPA receptor GluR2 phosphorylation for cerebellar long-term depression. Science 300:1751-1755.

Cook RG, Geller AI, Zhang G, Gowda R (2004) Touchscreen enhanced visual learning in rats. Behav Res Methods Instrum Comput 36:101-106.

Dichter MA (1978) Rat cortical neurons in cell culture: culture methods, cell morphology, electrophysiology, and synapse formation. Brain Res 149:279-293.

Di Iorio P, Battaglia G, Ciccarelli R, Ballerini P, Giuliani P, Poli A, Nicoletti F, Caciagli F (1996) Interaction between Al adenosine and class II metabotropic glutamate receptors in the regulation of purine and glutamate release from rat hippocampal slices. J Neurochem 67:302-309.

Dudai Y (1989) The neurobiology of memory. Oxford: Oxford UP.

Erickson CA, Jagadeesh B, Desimone R (2000) Clustering of perirhinal neurons with similar properties following visual experience in adult monkeys. Nat Neurosci 3:1143-1148.

Feasey KJ, Lynch MA, Bliss TV (1986) Long-term potentiation is associated with an increase in calcium-dependent, potassium-stimulated release of $\left[{ }^{14} \mathrm{C}\right]$ glutamate from hippocampal slices: an ex vivo study in the rat. Brain Res 364:39-44.

Fraefel C, Song S, Lim F, Lang P, Yu L, Wang Y, Wild P, Geller AI (1996) Helper virus-free transfer of herpes simplex virus type 1 plasmid vectors into neural cells. J Virol 70:7190-7197.

Fujita I, Tanaka K, Ito M, Cheng K (1992) Columns for visual features of objects in monkey inferotemporal cortex. Nature 360:343-346.

Hanks SK, Quinn AM, Hunter T (1988) The protein kinase family: conserved features and deduced phylogeny of the catalytic domains. Science 241:42-52.

Hernandez AI, Blace N, Crary JF, Serrano PA, Leitges M, Libien JM, Weinstein G, Tcherapanov A, Sacktor TC (2003) Protein kinase M zeta synthesis from a brain mRNA encoding an independent protein kinase $\mathrm{C}$ zeta catalytic domain. Implications for the molecular mechanism of memory. J Biol Chem 278:40305-40316.

Hokfelt T, Martensson A, Bjorklund A, Kleinau S, Goldstein M (1984) Distribution maps of tyrosine hydroxylase immunoreactive neurons in the rat brain. In: Handbook of chemical neuroanatomy; classical transmitters in the CNS, Pt I (Bjorklund A, Hokfelt T, eds), pp 277-379. New York: Elsevier.

Holscher C, Rolls ET, Xiang J (2003) Perirhinal cortex neuronal activity related to long-term familiarity memory in the macaque. Eur J Neurosci 18:2037-2046.

Hulo S, Alberi S, Laux T, Muller D, Caroni P (2002) A point mutant of GAP-43 induces enhanced short-term and long-term hippocampal plasticity. Eur J Neurosci 15:1976-1982.

Kaneko T, Kang Y, Mizuno N (1995) Glutaminase-positive and glutaminase-negative pyramidal cells in layer VI of the primary motor and somatosensory cortices: a combined analysis by intracellular staining and immunocytochemistry in the rat. J Neurosci 15:8362-8377.

Kano M, Hashimoto K, Chen C, Abeliovich A, Aiba A, Kurihara H, Watanabe $\mathrm{M}$, Inoue $\mathrm{Y}$, Tonegawa S (1995) Impaired synapse elimination during cerebellar development in PKC gamma mutant mice. Cell 83:1223-1231.

Kishimoto A, Mikawa K, Hashimoto K, Yasuda I, Tanaka S, Tominaga M, Kuroda T, Nishizuka Y (1989) Limited proteolysis of protein kinase C subspecies by calcium-dependent neutral protease (calpain). J Biol Chem 264:4088-4092.

Ling DS, Benardo LS, Serrano PA, Blace N, Kelly MT, Crary JF, Sacktor TC (2002) Protein kinase Mzeta is necessary and sufficient for LTP maintenance. Nat Neurosci 5:295-296.

Lyford GL, Yamagata K, Kaufmann WE, Barnes CA, Sanders LK, Copeland NG, Gilbert DJ, Jenkins NA, Lanahan AA, Worley PF (1995) Arc, a growth factor and activity-regulated gene, encodes a novel cytoskeletonassociated protein that is enriched in neuronal dendrites. Neuron 14:433-445.

Malenka RC, Nicoll RA (1999) Long-term potentiation-a decade of progress? Science 285:1870-1874.

Markham MR, Butt AE, Dougher MJ (1996) A computer touch-screen apparatus for training visual discriminations in rats. J Exp Anal Behav 65:173-182.

Mishkin M, Murray EA (1994) Stimulus recognition. Curr Opin Neurobiol 4:200-206.

Mitterdorfer J, Bean BP (2002) Potassium currents during the action potential of hippocampal CA3 neurons. J Neurosci 22:10106-10115.

Moser MB, Moser EI, Forrest E, Andersen P, Morris RG (1995) Spatial learning with a minislab in the dorsal hippocampus. Proc Natl Acad Sci USA 92:9697-9701.

Mumby DG, Pinel JP (1994) Rhinal cortex lesions and object recognition in rats. Behav Neurosci 108:11-18.

Naber PA, Witter MP, Lopes da Silva FH (2000) Differential distribution of barrel or visual cortex. Evoked responses along the rostro-caudal axis of the peri- and postrhinal cortices. Brain Res 877:298-305.

Nichols RA, Haycock JW, Wang JK, Greengard P (1987) Phorbol ester enhancement of neurotransmitter release from rat brain synaptosomes. J Neurochem 48:615-621.

Oh JD, Geller AI, Zhang G, Chase TN (2003) Gene transfer of constitutively active protein kinase $\mathrm{C}$ into striatal neurons accelerates onset of levodopainduced motor response alterations in parkinsonian rats. Brain Res 971:18-30.

Olds JL, Golski S, McPhie DL, Olton D, Mishkin M, Alkon DL (1990) Discrimination learning alters the distribution of protein kinase $\mathrm{C}$ in the hippocampus of rats. J Neurosci 10:3707-3713.

Paxinos G, Watson C (1986) The rat brain in stereotaxic coordinates. Sydney: Academic.

Powell CM, Johnston D, Sweatt JD (1994) Autonomously active protein kinase $\mathrm{C}$ in the maintenance phase of $\mathrm{N}$-methyl-D-aspartate receptorindependent long term potentiation. J Biol Chem 269:27958-27963.

Powell KA, Valova VA, Malladi CS, Jensen ON, Larsen MR, Robinson PJ (2000) Phosphorylation of dynamin I on Ser-795 by protein kinase C blocks its association with phospholipids. J Biol Chem 275:11610-11617.

Ramakers GM, McNamara RK, Lenox RH, De Graan PN (1999) Differential changes in the phosphorylation of the protein kinase $\mathrm{C}$ substrates myristoylated alanine-rich $\mathrm{C}$ kinase substrate and growth-associated protein43/B-50 following Schaffer collateral long-term potentiation and longterm depression. J Neurochem 73:2175-2183.

Rapp PR, Deroche PS, Mao Y, Burwell RD (2002) Neuron number in the parahippocampal region is preserved in aged rats with spatial learning deficits. Cereb Cortex 12:1171-1179.

Robinson PJ, Sontag JM, Liu JP, Fykse EM, Slaughter C, McMahon H, Sudhof TC (1993) Dynamin GTPase regulated by protein kinase C phosphorylation in nerve terminals. Nature 365:163-166.

Routtenberg A (1999) Tagging the Hebb synapse. Trends Neurosci 22:255-256.

Routtenberg A, Cantallops I, Zaffuto S, Serrano P, Namgung U (2000) Enhanced learning after genetic overexpression of a brain growth protein. Proc Natl Acad Sci USA 97:7657-7662.

Rumelhart DE, McClelland JL, Group PR (1986) Parallel distributed processing. Cambridge, MA: MIT.

Seidenman KJ, Steinberg JP, Huganir R, Malinow R (2003) Glutamate receptor subunit 2 Serine 880 phosphorylation modulates synaptic transmission and mediates plasticity in CA1 pyramidal cells. J Neurosci 23:9220-9228.

Snodgrass SR, White WF, Biales B, Dichter M (1980) Biochemical correlates of GABA function in rat cortical neurons in culture. Brain Res 190:123-138.

Song S, Wang Y, Bak SY, During MJ, Bryan J, Ashe O, Ullrey DB, Trask LE, Grant FD, O’Malley KL, Riedel H, Goldstein DS, Neve KA, LaHoste GJ, Marshall JF, Haycock JW, Neve RL, Geller AI (1998) Modulation of rat rotational behavior by direct gene transfer of constitutively active protein kinase C into nigrostriatal neurons. J Neurosci 18:4119-4132.

Sun M, Kong L, Wang X, Holmes C, Gao Q, Zhang W, Pfeilschifter J, Goldstein DS, Geller AI (2004) Coexpression of tyrosine hydroxylase, GTP cyclohydrolase I, aromatic amino acid decarboxylase, and vesicular monoamine transporter-2 from a helper virus-free HSV-1 vector supports high-level, long-term biochemical and behavioral correction of a rat model of Parkinson's disease. Hum Gene Ther 15:1177-1196.

Tanaka C, Nishizuka Y (1994) The protein kinase C family for neuronal signaling. Annu Rev Neurosci 17:551-567.

Tang YP, Shimizu E, Dube GR, Rampon C, Kerchner GA, Zhuo M, Liu G, Tsien JZ (1999) Genetic enhancement of learning and memory in mice. Nature 401:63-69.

Tingley WG, Ehlers MD, Kameyama K, Doherty C, Ptak JB, Riley CT, Huganir RL (1997) Characterization of protein kinase A and protein kinase C phosphorylation of the $N$-methyl-D-aspartate receptor NR1 subunit using phosphorylation site-specific antibodies. J Biol Chem 272:5157-5166. 
Tsien JZ, Huerta PT, Tonegawa S (1996) The essential role of hippocampal CA1 NMDA receptor-dependent synaptic plasticity in spatial memory. Cell 87:1327-1338.

Wan H, Aggleton JP, Brown MW (1999) Different contributions of the hippocampus and perirhinal cortex to recognition memory. J Neurosci 19:1142-1148.

Wang X, Zhang G, Sun M, Geller AI (2001) General strategy for constructing large HSV-1 plasmid vectors that co-express multiple genes. BioTechniques 31:204-212.

Wang X, Mori T, Sumii T, Lo EH (2002) Hemoglobin-induced cytotoxicity in rat cerebral cortical neurons: caspase activation and oxidative stress. Stroke 33:1882-1888.

Waters J, Smith SJ (2000) Phorbol esters potentiate evoked and spontane- ous release by different presynaptic mechanisms. J Neurosci 20:7863-7870.

Weeber EJ, Atkins CM, Selcher JC, Varga AW, Mirnikjoo B, Paylor R, Leitges $\mathrm{M}$, Sweatt JD (2000) A role for the $\beta$ isoform of protein kinase $\mathrm{C}$ in fear conditioning. J Neurosci 20:5906-5914.

Zhang G, Wang X, Yang T, Sun M, Zhang W, Wang Y, Geller AI (2000) A tyrosine hydroxylase-neurofilament chimeric promoter enhances longterm expression in rat forebrain neurons from helper virus-free HSV-1 vectors. Mol Brain Res 84:17-31.

Zheng X, Zhang L, Wang AP, Bennett MV, Zukin RS (1999) Protein kinase $\mathrm{C}$ potentiation of $N$-methyl-D-aspartate receptor activity is not mediated by phosphorylation of $N$-methyl-D-aspartate receptor subunits. Proc Natl Acad Sci USA 96:15262-15267. 